\title{
Optimized integration of renewable energy technologies into Alberta's oil sands industry
}

\author{
Mohamed Elsholkami ${ }^{a}$, Ali Elkamel ${ }^{a, *}$, Francisco Vargas $^{\mathrm{b}}$ \\ a Department of Chemical Engineering, University of Waterloo, Waterloo, Canada \\ ${ }^{\mathrm{b}}$ Department of Chemical Engineering, Rice University, TX, United States
}

\section{A R T I C L E I N F O}

\section{Article history:}

Received 23 August 2015

Received in revised form 1 February 2016

Accepted 23 March 2016

Available online 29 March 2016

\section{Keywords:}

Process system engineering

Oil sands

Renewable energy

Mathematical modeling

Process optimization

Process modeling

Carbon management

\begin{abstract}
A B S T R A C T
An energy optimization model for the integration of renewable technologies into the energy infrastructure of the oil sands industry is presented. The proposed model determines the optimal configuration of oil producers and the energy infrastructure required to meet their energy demands. The model is geared toward the minimization of cost subject to carbon dioxide emission constraints. A mixed integer non-linear optimization model is developed that simultaneously optimizes capacity expansion and new investment decisions of conventional and renewable energy technologies. To illustrate its applicability, the proposed model was applied to a case study using data reported in the literature for various years of oil sands operations. A rolling horizon approach was implemented to determine the effect of investment decisions of previous operational years on the selection of new investment options. Results were compared with and without the incorporation of renewable energy technologies. The results obtained indicate that the proposed model is a practical tool that can be employed to evaluate and plan oil sands and energy producers for future scenarios. Moreover, the results show that renewable energy technologies have significant potential in reducing reliance on fossil-fuel based technologies and their associated $\mathrm{CO}_{2}$ emissions. The emission constraints set for the operational year 2025 can only be achieved by the incorporation of renewables in the energy production mix.
\end{abstract}

(c) 2016 Elsevier Ltd. All rights reserved.

\section{Introduction}

\subsection{Alberta's oil sands industry-current and future challenges}

The majority of oil reserves in Canada are located in the Western Canada Sedimentary Basin, of which the oil sands in Alberta comprise the majority of reserves. The majority of Canadian oil sands are located in Alberta in three major deposits, which are Peace River, Cold Lake and Athabasca. The largest and most heavily developed among them is the Athabasca oil sands deposit, which includes deposits that can be surface mined and extensive in situ reserves. The Canadian Oil Sands is the third largest crude oil proven reserves in the world, which amount to proven reserves of about 168 billion barrels constituting approximately $97 \%$ of Canada's total oil reserves (Woynillowicz, 2005; National Energy Board, 2006).

The oil sands are a mixture of bitumen, sand, clay and water. Bitumen is a heavy viscous crude that requires significant amounts of energy for production, upgrading and transportation. Extracted bitumen can be diluted by solvents (e.g., naphtha) to reduce

\footnotetext{
* Corresponding author.

E-mail address: aelkamel@uwaterloo.ca (A. Elkamel).
}

its viscosity for further transportation to be sold as commercial crude bitumen or to be upgraded to higher quality synthetic crude oil (SCO). Bitumen upgrading operations can be integrated with mining or steam assisted gravity drainage (SAGD) extraction operations, and they typically consist of hydrocracking or thermocracking processes to break the heavy hydrocarbon molecules into lighter ones. Mining extraction is typically employed for bitumen deposits located at depths up to $75 \mathrm{~m}$. The oil sands are mined by electric and hydraulic shovels, which are then transported by trucks to separation units in which hot water and solvents are used to extract the bitumen from the oil sands mixture. In-situ methods are used for deep bitumen deposits that are located more than $75 \mathrm{~m}$ below the earth's surface, and they have been employed to recover deposits at depths within the range of $350-600 \mathrm{~m}$ below the surface. In-situ methods rely on the use of steam, solvents or thermal energy to extract the bitumen from the oil sands in order to enhance its flow, which is then pumped to the surface. The two prominent production technologies are mining and in-situ, the latter being more economically and environmentally preferable and will account to approximately two-thirds of future oil sands production capacity. Mining extraction is currently the dominant method used for bitumen extraction (National Energy Board, 2006; Oil Sands Discovery Centre, 2014; Kubik, 2013). 


$\begin{array}{ll}\text { Nomenclatures } \\ \text { Indices } & \\ b & \text { Type of steam and hot water boilers } \\ e & \text { Type of existing energy production technology } \\ h & \text { Type of hydrogen production technology } \\ i & \text { Type of energy production technology } \\ m & \text { Type of integrated mining/upgrading SCO produc- } \\ & \text { tion route } \\ o & \text { Type of SCO production route } \\ p & \text { Type of power production technology } \\ s & \text { Type of integrated SAGD/upgrading SCO production } \\ & \text { route }\end{array}$

Sets

$B \quad$ Set of boilers

E Set of existing energy production units (i.e., power, hydrogen, steam and hot water producers)

$H \quad$ Set of hydrogen production plants

I Set of all energy production technologies

$M \quad$ Set of integrated mining/upgrading SCO production routes

$O \quad$ Set of all SCO production routes

$P \quad$ Set of power production plants

$S \quad$ Set of integrated SAGD/upgrading SCO production routes

\section{Parameters}

AWP Annual energy yield of VESTAS wind turbine (kWh) $\mathrm{CCB}_{b} \quad$ Amortized capital cost of boiler type $b$ (\$/year)

CCGEO Amortized capital cost of geothermal plants (\$/year)

$\mathrm{CCH}_{h} \quad$ Amortized capital cost of hydrogen plant type $h$ (\$/year)

CCHE Amortized capital cost of electrolyzer (\$/year)

$\mathrm{CCP}_{p} \quad$ Amortized capital cost of power plant type $\mathrm{p}$ (\$/year)

$\mathrm{CO}_{2} \mathrm{E}$ Maximum allowable level of $\mathrm{CO}_{2}$ emissions (ton $\mathrm{CO}_{2} / \mathrm{h}$ )

$d_{m} \quad$ Distance between mining location and extraction plant $(\mathrm{m})$

DR Fraction of diluent

$\mathrm{dT}_{m} \quad$ Distance between extraction plant and tailing ponds (m)

ECB Electricity requirement for the production of commercial crude bitumen (kWh/ton)

$\mathrm{ECC}_{i}$ Electricity requirement for compressing $\mathrm{CO}_{2}$ for transport (kWh/ton/km)

ECR Power requirement for centrifugation $\left(\mathrm{kWh} / \mathrm{m}^{3}\right)$

$\mathrm{ED}_{0} \quad$ Electricity requirement for delayed cokers (kWh/ton)

EER Electrolyzer energy requirement (kWh/Nm3)

$\mathrm{EL}_{0} \quad$ Electricity requirement for LC-finers ( $\mathrm{kWh} / \mathrm{ton}$ )

EPVF Annuity factor for existing technologies

ESMR Electricity requirement of steam methane reforming plants $\left(\mathrm{kW} /\right.$ ton $\left.\mathrm{H}_{2}\right)$

$\triangle$ HSS Change in enthalpy of SAGD steam (MJ/ton)

$\triangle$ HPS Change in enthalpy of process steam (MJ/ton)

$\triangle \mathrm{HHW}$ Change in enthalpy of hot water (MJ/ton)

HHG Hydrogen requirement for hydrotreatment of $\mathrm{HGO}$ (ton $\mathrm{H}_{2}$ /ton LGO)

$\mathrm{HH}_{h}^{\max }$ Maximum production capacity of hydrogen plant $h$ (ton/h)

$\mathrm{HHV}_{b} \quad$ High heating value of fuel used in boiler technology $b$ i.e., natural gas, biomass etc. (MJ/ton)

$\mathrm{HHV}_{h} \quad$ High heating value of fuel used in hydrogen technology $h$ i.e., coal, natural gas, etc. (MJ/ton)
$\mathrm{HHV}_{p} \quad$ High heating value of fuel used in power technology $p$ i.e., coal, natural gas, etc. (MJ/ton)

HLG Hydrogen requirement for hydrotreatment of LGO (ton $\mathrm{H}_{2}$ /ton $\mathrm{LGO}$ )

HN Hydrogen requirement for the hydrotreatment of naphtha (ton $\mathrm{H}_{2}$ /ton naphtha)

HNG Heating value of natural gas $\left(\mathrm{GJ} / \mathrm{Nm}^{3}\right)$

$\mathrm{HP}_{h}^{\text {cogen }}$ Power co-produced or consumed by hydrogen plants ( $\mathrm{kW} /$ ton $\mathrm{H}_{2}$ )

$\mathrm{HRP}_{p} \quad$ Heat rate of power plant $p(\mathrm{MJ} / \mathrm{kWh})$

$\mathrm{HRH}_{h} \quad$ Heating rate of hydrogen production technology $h$ $\left(\mathrm{MJ} /\right.$ ton $\left.\mathrm{H}_{2}\right)$

$\mathrm{HRU}_{0} \quad$ Hydrogen requirement for hydrocracking in low and high conversion LC-finers (ton $\mathrm{H}_{2}$ /ton feed)

HRGEO $^{\text {max }}$ Maximum heat rate provided by a geothermal plant $(\mathrm{MJ} / \mathrm{h})$

$\mathrm{FR}_{0} \quad$ Natural gas requirement for LC-finers and delayed cokers (GJ/ton VTB)

$L \quad$ Length of $\mathrm{CO}_{2}$ pipeline $(\mathrm{km})$

MDC Diesel consumption for mining extraction ( $\mathrm{L}$ diesel/bbl bitumen)

$\eta_{b} \quad$ Efficiency of boiler type $b$

$\mathrm{OMB}_{b} \quad$ Operating and maintenance cost of boiler type $b$ (\$/year)

OMGEO Operating and maintenance cost of geothermal plants (\$/year)

$\mathrm{OMH}_{h} \quad$ Operating and maintenance cost of hydrogen plant $h(\$ /$ year $)$

OMHE Operating and maintenance cost of electrolyzer (\$/year)

$\mathrm{OMP}_{p} \quad$ Operating and maintenance cost of power plant $p$ (\$/year)

$\mathrm{PFB}_{b} \quad$ Unit cost of fuel utilized by SAGD boiler $b(\$ / G$ or $\$ /$ ton)

$\mathrm{PF}_{m} \quad$ Pumping factor for hydrotransport (kWh/ton/m)

$\mathrm{PFH}_{h} \quad$ Unit cost of fuel utilized by hydrogen plant $h(\$ / \mathrm{GJ}$ or $\$ /$ ton)

$\mathrm{PFP}_{p} \quad$ Unit cost of fuel utilized by power plant $p(\$ / \mathrm{G}$ or $\$ /$ ton)

$\mathrm{PFT}_{m}$ Pumping factor for transport of tailings $(\mathrm{kWh} / \mathrm{ton} / \mathrm{m})$

PD Unit cost of diesel (\$/L)

PNG Unit cost of natural gas utilized by natural gas boilers $(\$ / G J)$

$\mathrm{PP}_{p}^{\max } \quad$ Maximum power production capacity of plant $p$ $(\mathrm{kWh})$

PVF Annuity factor for newly established technologies

$\mathrm{EPVF}_{e} \quad$ Annuity factor for existing technologies

$S_{b}^{\max } \quad$ Maximum production capacity of boiler type $b$ (ton/h)

SSC Unit sequestration cost $\left(\$ /\right.$ ton $\left.\mathrm{CO}_{2}\right)$

$\mathrm{SC}_{m} \quad$ Steam requirement for conditioning stage (ton steam/ton feed)

SF Steam requirement for bitumen extraction (ton steam/ton froth)

SOR Steam to oil ratio (ton of steam/ton of bitumen)

SRD Steam requirement for the diluent recovery unit (ton steam/ton feed)

SRF Steam requirement for the fluid coker (ton steam/ton feed) 
SRV Steam requirement of vacuum distillation units (ton steam/ton feed)

$t \quad$ Annual hours of operation $(8760 \mathrm{~h} /$ year $)$

TC Unit transportation cost of $\mathrm{CO}_{2}\left(\$ /\right.$ ton $\left.\mathrm{CO}_{2} / \mathrm{km}\right)$

$\mathrm{WC}_{m} \quad$ Water requirement for conditioning (ton water/ton oil sands)

WH Water requirement for hydrotransport (ton water/ton oil sands)

WR Water requirement for bitumen recovery (ton water/ton oil sands)

WTCF Wind turbine capacity factor

\%RED Percentage reduction of $\mathrm{CO}_{2}$ emission levels

$\% S \quad$ Fraction of boiler capacity dedicated for steam production

Binary variables

$\mathrm{EGEO}_{e}=1$ if existing geothermal plant number $e$ is operating in the investigated year; 0 otherwise

$\mathrm{ENB}_{b e} \quad=1$ if existing boiler number e of type $b$ is operating in the investigated year; 0 otherwise

$\mathrm{ENH}_{h e} \quad=1$ if existing hydrogen plant number $e$ of type $h$ is operating in the investigated year; 0 otherwise

ENHE $_{e}=1$ if existing electrolyzer is operating in the investigated year; 0 otherwise

$\mathrm{ENP}_{p e} \quad=1$ if existing power plant number e of type $p$ is operating in the investigated year; 0 otherwise

$\mathrm{EWT}_{e} \quad=1$ if existing wind turbine number $e$ is operating in the investigated year; 0 otherwise

IMBIT $_{m}=1$ if integrated mining upgrading route is selected; 0 otherwise

ISBIT $_{S}=1$ if integrated SAGD upgrading route is selected; 0 otherwise

\section{Integer variables}

$\mathrm{NB}_{b} \quad$ Number of newly installed boilers of type $b$

NGEO Number of newly installed geothermal plant

$\mathrm{NH}_{h} \quad$ Number of new installed hydrogen plant $h$

NHE Number of new electrolyzers

$\mathrm{NP}_{p} \quad$ Number of newly installed power plant $p$

NWT Number of newly installed wind turbines

\section{Continuous variables}

A Annual cash flow (\$/year)

$\mathrm{ATB}_{0} \quad$ Atmospheric topped bitumen fraction sent to vacuum distillation unit and/or LC-finers (ton/h)

$\mathrm{ATBF}_{o} \quad$ Atmospheric topped bitumen transferred from the DRU to the fluid cokers (ton/h)

$\mathrm{BIT}_{m} \quad$ Amount of bitumen produced from mining production route $m$ (ton/h)

$\mathrm{BIT}_{S} \quad$ Amount of bitumen produced from SAGD production route $s$ (ton/h)

$\mathrm{BMF}_{m} \quad$ Bitumen froth in primary extraction (ton froth/h)

$\mathrm{BF}_{0} \quad$ Amount of bottoms from LC-fining sent to fluid cokers in combined thermocracking and hydrocracking upgrading route (ton/h)

$\mathrm{C}_{i} \quad$ Amount of $\mathrm{CO}_{2}$ captured from power and hydrogen plants (ton $\mathrm{CO}_{2} / \mathrm{h}$ )

CB Flow rate of commercial bitumen (ton/h)

CCPD Total power requirement for carbon capture and transportation (kWh)

CCSC Total net present value of carbon capture and sequestration cost $(\$)$
$\mathrm{CO}_{2} e_{i} \quad \mathrm{CO}_{2}$ emission of energy producer $i\left(\operatorname{ton} \mathrm{CO}_{2} / \mathrm{h}\right.$ )

$\mathrm{CO}_{2} \mathrm{~T}$ Total $\mathrm{CO}_{2}$ emission of energy producers (ton $\mathrm{CO}_{2} / \mathrm{h}$ )

$\mathrm{CSCP}_{p}$ Total $\mathrm{CO}_{2}$ captured from power technology $p$ (ton $\mathrm{CO}_{2} / \mathrm{h}$ )

$\mathrm{CSCH}_{h}$ Total $\mathrm{CO}_{2}$ captured from power technology $h$ (ton $\mathrm{CO}_{2} / \mathrm{h}$ )

$\mathrm{DBC}_{m} \quad$ Amount of diluted bitumen transferred to the centrifugation stages $\left(\mathrm{m}^{3} / \mathrm{h}\right)$

EFC Total net present value of extraction fuel (NG + Diesel) cost (\$)

$\mathrm{FH}_{h} \quad$ Amount of fuel consumed by hydrogen plant $h$ (fuel/h, e.g., $\mathrm{Nm}^{3}$ of $\mathrm{NG} / \mathrm{h}$ )

$\mathrm{FP}_{p} \quad$ Amount of fuel consumed by power plant $p$ (unit fuel/h, e.g., $\mathrm{Nm}^{3}$ of $\mathrm{NG} / \mathrm{h}$ )

GW Hot water produced by a geothermal plant (ton/h)

HC Total net present value of hydrogen production cost (\$)

$\mathrm{HGO}_{o} \quad$ Heavy gas oil flow rate (ton/h)

$\mathrm{HH}_{h} \quad$ Hydrogen produced by plant $h$ (ton $\mathrm{H}_{2} / \mathrm{h}$ )

HHE Hydrogen produced by electrolyzers (ton $\mathrm{H}_{2} / \mathrm{h}$ )

HRGEO Heat rate provided by a geothermal plant (MJ/h)

$\mathrm{HW}_{b} \quad$ Total amount of hot water produced by boiler type $b$ (ton/h)

HWGC Total net present value of geothermal hot water production cost (\$)

$\mathrm{LGO}_{0} \quad$ Light gas oil flow rate (ton/h)

MEDD Total diesel demand for mining extraction $(\mathrm{L} / \mathrm{h})$

MEPD Total power demand for mining extraction (kWh)

MEPSD Total process steam demand for mining extraction (ton $/ \mathrm{h}$ )

MEWD Total hot water demand for mining extraction (ton/h)

$\mathrm{MO}_{m} \quad$ Oil sands mining rate (ton oil sands/h)

$N_{0} \quad$ Naphtha flow rate (ton/h)

NPV Total net present value of energy production cost for oil sands operations (\$)

PC Total net present value of power cost (\$)

$\mathrm{PH}_{h} \quad$ Power co-produced or consumed by hydrogen (kWh)

$\mathrm{PP}_{p} \quad$ Electricity produced by power plant $p(\mathrm{kWh})$

$\mathrm{PS}_{b} \quad$ Total process steam produced by boiler $b$ (ton/h)

PWT Total power production by wind turbines (kWh)

$\mathrm{SC}_{m} \quad$ Process steam consumption for conditioning stage (ton steam/ton oil sand)

SEPD Total power demand for SAGD extraction operations (kWh)

SESD Total SAGD steam demand (ton $/ \mathrm{h}$ )

SF Process steam required for mining bitumen extraction (ton steam/ton froth)

$\mathrm{SL}_{m} \quad$ Oil sands slurry rate (ton/h)

SMRPD Total power requirement of SMR plants (kWh)

$\mathrm{SS}_{b} \quad$ Total SAGD steam produced by boiler $b$ (ton/h)

SC Total net present value of steam production cost (\$)

$\mathrm{TPE}_{m} \quad$ Tailings production from primary extraction stage (ton/h)

$\mathrm{TSE}_{m} \quad$ Tailings production from secondary extraction stage (ton/h)

UHD Total hydrogen demand for hydrocracking and hydrotreatment stages in upgrading operations (ton $\mathrm{H}_{2} / \mathrm{h}$ )

UFD Total fuel demand (natural gas) for upgrading operations $(\mathrm{GJ} / \mathrm{h})$ 


\begin{tabular}{|c|c|}
\hline UPD & $\begin{array}{l}\text { Total power requirement for upgrading operations } \\
(\mathrm{kWh})\end{array}$ \\
\hline UPSD & $\begin{array}{l}\text { Total process steam requirement for upgrading } \\
\text { operations (ton } / \mathrm{h} \text { ) }\end{array}$ \\
\hline $\mathrm{VTB}_{0}$ & $\begin{array}{l}\text { Vacuum topped bitumen feed to LC-finers or } \\
\text { delayed cokers (ton } / \mathrm{h} \text { ) }\end{array}$ \\
\hline $\mathrm{XB}_{b}$ & $\begin{array}{l}\text { Amount of fuel consumed by steam boiler } b \text { (unit } \\
\text { fuel/h, e.g., } \mathrm{Nm}^{3} \text { of } \mathrm{NG} / \mathrm{h} \text { ) }\end{array}$ \\
\hline \multicolumn{2}{|c|}{ Acronyms } \\
\hline ATB & Atmospheric topped bitumen \\
\hline $\mathrm{BCL}$ & Battelle columbus laboratory biomass gasifiers \\
\hline CCS & Carbon capture and sequestration \\
\hline DC & Delayed coker \\
\hline DRU & Diluent recovery unit \\
\hline EGS & Enhance geothermal system \\
\hline $\mathrm{FC}$ & Fluid coker \\
\hline GHG & Greenhouse gas emissions \\
\hline GTI & Gas technology institute biomass gasifiers \\
\hline HGO & Heavy gas oil \\
\hline HT & Hydrotreatment \\
\hline IGCC & Integrated gasification combined cycle \\
\hline LCF & LC-fining \\
\hline LGO & Light gas oil \\
\hline MP1 & $\begin{array}{l}\text { Mined bitumen }+ \text { conditioning upgraded by } \\
\mathrm{LCF}+\mathrm{FC}+\mathrm{HT}\end{array}$ \\
\hline MP2 & Mined bitumen upgraded by LCF + FC + HT \\
\hline MP3 & Mined bitumen upgraded by DC $+\mathrm{HT}$ \\
\hline MP4 & Mined bitumen upgraded by LCF $+\mathrm{HT}$ \\
\hline NGCC & Natural gas combined cycle \\
\hline NPV & Net present value \\
\hline SAGD & Steam assisted gravity drainage \\
\hline SCO & Synthetic crude oil \\
\hline SCPC & Supercritical pulverized coal \\
\hline SOR & Steam-to-oil ratio \\
\hline SP1 & SAGD bitumen upgraded by LCF + FC + HT \\
\hline SP2 & SAGD bitumen upgraded by $\mathrm{DC}+\mathrm{HT}$ \\
\hline SP3 & SAGD bitumen upgraded by LCF + HT \\
\hline VDU & Vacuum distillation unit \\
\hline
\end{tabular}

Continued reliance on crude oil is expected to persist in future years and dominated the world's energy supply. Global oil demand is expected to reach 111 million barrels per day by 2040 (World Oil Outlook, 2014), and approximately one fourth of this oil will be supplied by Canada and the United States. The continuing decline of conventional crude oil resources is increasing the reliance on unconventional crude oil production (e.g., bitumen).

The significant drop in oil prices that occurred in 2014 has a major negative impact on Canada's economy. By taking into consideration the forecasted oil price profiles, it is estimated that the damage to Alberta's gross domestic product will be around 0.8 parts per thousand in 2015, which would eliminate the chance of falling into a recession with a growth rate maintained at $2.7 \%$ (Noronha, 2015). Therefore, it is expected that development of oil sands projects will continue as planned and the production of Canadian unconventional oil will continue on an increasing trend. The situation is likely to resemble that of the recession in 2008-2009, in which oil production of Alberta continued to rise steadily as oil sands producers adopted the view of long term market conditions (Isfeld, 2015; Mckenna, 2015; Ferley et al., 2014). However, there are uncertainties associated with the further development of the oil sands industry as a result of the concerns associated with the availability of energy commodities (e.g., power, steam, etc.). Moreover, environmental issues regarding the greenhouse gas (GHG) emissions associated with the production of the energy commodities required for oil sands operations represent a major concern for Alberta provincial and Canadian federal governments, and their management is essential for sustaining the further development of oil sands operations (Huot and Grant, 2012).

Availability of energy commodities (i.e., power, hydrogen, steam, etc.) and managing the environmental impacts of production while maintaining economic feasibility are a crucial factor to the further development of the oil sands industry. Under the United Nations Framework and Kyoto protocol Canada is obligated to reduce GHG emissions to achieve international environmental standards. This in return has focused efforts of research on the development of sustainable energy pathways that impose minimum environmental burdens (Huot and Grant, 2012; Doritsch et al., 2010).

Operations of oil sands require significant amounts of energy, which are derived from burning natural gas, making the industry the largest contributor to the growth of GHG emissions in Canada, and an increase in production offsets achieved reductions in their intensity (National Energy Board, 2006). The natural gas supporting the energy production for the oil sands industry is obtained from the Mackenzie Basin south through the Mackenzie Valley Pipeline, which is currently in regulation processes. It is projected that by 2025 the oil sands operations will require 1.6-2.3 billion cubic feet of natural gas daily, which is equivalent to the maximum capacity of the Mackenzie pipeline that also provides natural gas used for heating Canadian homes. All of these factors contribute to the requirement of diversifying the energy infrastructure of the oil sands industry (Clarke, 2010). A potential alternative source of energy for the oil sands industry is nuclear energy, which was recently considered to provide steam and electricity for bitumen extraction and upgrading operations. Nuclear based technologies have near zero emissions associated with their operations, and the commodities produced can replace natural gas based plants significantly reducing emission intensity. The environmental impacts and public perceptions of the risks associated with employing nuclear technologies present a major resistance to their penetration in the energy infrastructure mix. There are various challenges associated with the introduction of nuclear based technologies in Alberta's energy infrastructure, which include public and government acceptance, environmental concerns associated with radioactive waste storage, water consumption, and very long construction times (Doucet, 2007).

Efficient and robust mathematical models that describe the operations of the Canadian oil sands industry are useful tools that can be used to assess current and future production scenarios, and their associated environmental impacts. These models are useful in order to determine the energy infrastructure required to meet the oil production demands projected over the upcoming years, which will be of great assistance as a decision making tool in planning future operations of the industry. Variability and uncertainties in key process operational parameters, such as natural gas prices, GHG emission targets, etc., can be evaluated easily using these modeling tools. Several models have been developed in previous studies to describe the operations of the oil sands industry. Ordorica-Garcia et al. (2007) modeled the energy demands and GHG emission of the oil sands industry. They formulated a mathematical model referred to as the oil sands operations model in order to estimate the energy requirements associated with SCO and bitumen production. Their formulations were based on production data available from current commercial oil sands operators. The production schemes incorporated in their model include integrated mining and upgrading, integrated in-situ extraction and upgrading, and diluted thermal bitumen production. In addition, 
they considered three different upgrading routes based on hydrocracking and thermocracking processes. The computation of GHG emissions associated with supplying the energy requirements (i.e., power, hydrogen, steam, hot water, natural gas, and diesel) for oil sands producers is also considered. They later developed a mixed integer linear programming optimization model that determines the optimal infrastructure required to meet the energy demands modeled in their previous work with an objective of minimizing total annual costs of energy supply that is subject to $\mathrm{CO}_{2}$ emission constraints (Ordorica-Garcia et al., 2008). In their model, only conventional power and hydrogen plants within the energy infrastructure were considered. They illustrated the applicability of the energy optimization model by investigating a case study of the oil sands operations for the year 2003. Their results included the quantified energy costs and emissions associated with bitumen and SCO production.

Betancourt-Torcat et al. (2011) later developed an optimization model that simultaneously determines the optimal energy infrastructure and oil sand production schemes, and referred to it as the integrated oil sands energy optimization model. In comparison to the work done by Ordorica-Garcia et al. (2008) the energy demands are not determined a priori, instead they are calculated internally in the optimization model since both energy and oil producers are set as decision variables. Their model was also formulated with the objective of minimizing total annual cost subject to $\mathrm{CO}_{2}$ emission constraints. They applied the model on two case studies for the operational years 2003 and 2020. In a later work they incorporated nuclear energy for power and steam production, and also imposed an additional environmental constraint (i.e., water withdrawal limits from the Athabasca River) (Betancourt-Torcat et al., 2012a). The model was formulated as a mixed integer non-linear programming model and was applied for a case study for the oil sands 2030 operational year. In a later study they investigated the effect of varying key environmental and operational parameters on the oil sands operations. These are $\mathrm{CO}_{2}$ capture levels, natural gas prices, and steam-to-oil ratios (SOR) (Betancourt-Torcat et al., 2013). The $\mathrm{CO}_{2}$ emission targets are expected to become increasingly stringent in order to satisfy emissions policies set by the government of Alberta. Natural gas prices and SOR are the two parameters that have the most significant impact on the total annual costs of producing SCO and commercial bitumen. They later extended their work to develop a stochastic optimization model that accounts for the uncertainty in natural gas prices and SOR (Betancourt-Torcat et al., 2012b). They also offered a comparison of the results of their deterministic and stochastic optimization models.

To the authors' knowledge all of the optimization models developed for the modeling of oil sands operations up to this point do not incorporate capacity expansion decisions, or incorporate renewable energy technologies in the proposed energy infrastructure. This paper introduces a new capacity expansion energy optimization model for the Canadian oil sands industry. It also presents an approach for the integration of renewable energy technologies in the Alberta oil sands energy infrastructure, and illustrates the effect of incorporating renewable energy production on reducing the reliance of the oil sands industry on fossil fuel resources (i.e., natural gas). A feature of the proposed model is the incorporation of capacity expansion decisions. A rolling horizon approach is implemented, in which the results obtained for a certain planning period are used as input for the following planning step. This allows for determining the effect of the existing energy infrastructure on new investment decisions, and allows for optimizing the capacity expansion decisions of both renewable and conventional energy production technologies. The key aspect in the proposed optimization model is the inclusion of renewable energy technologies as potential resources to provide energy for oil sands producers.

\subsection{Renewable energy potential in Alberta}

Renewable energy production can provide significant potential in reducing GHG emissions in Alberta. An assessment of selected renewable energy technologies that was conducted by the government of Alberta provides insight on the potential of renewable energy production in Alberta. The criteria used to conduct the assessment included applicability to Alberta, level of commercialization, environmental footprint and cost (Price Water House Coopers, 2009).

The potential of integrating renewable energy technologies depends significantly on their applicability to Alberta's physical characteristics. The results obtained indicated that geothermal, Enhanced Geothermal Systems (EGS), hydropower and wind are the most complimentary to Alberta's physical environment. On the other hand, Concentrated Solar Power technologies required minimum direct normal irradiance values that are higher than the average available in Alberta. Solar PV showed strong compatibility with Alberta; however, their potential is only limited to small scale applications (e.g., residential). Over the past few decades wind and hydropower had high levels of commercialization in various European countries and over Canada. Technologies, such as EGS have low levels of commercialization and their implementation is not considered to be viable in the near future. Geothermal and EGS systems have GHG emissions relatively higher than those of other renewable technologies considered in the conducted evaluation. However, these emissions are negligible in comparison with fossil-fuel based energy production technologies. For example, geothermal plants emissions range from near-zero emissions to $5 \%$ of the $\mathrm{CO}_{2}, 1 \%$ of the $\mathrm{SO}_{2}$, and less than $1 \%$ of the $\mathrm{N}_{2} \mathrm{O}$ emitted by coal-fired plants of a similar size (Price Water House Coopers, 2009).

\subsubsection{Geothermal}

There are two major incentives for utilizing geothermal energy in oil sands operations, which are natural gas cost, and reduction in GHG emission intensity. Most of the energy utilized for heating water for oil sands operations is obtained from natural hydrocarbons or by heat recovery techniques in cogeneration technologies. Significant efforts are being made to implement alternative sources of thermal energy. Low-grade geothermal heat can economically compete with burning natural gas and reduce the overall demand for it (Holm et al., 2012).

In the Athabasca region of Northern Alberta heat is present at depths within the earth, and to extract thermal energy in such a region requires artificially created porosity (i.e., fractures) and fluids injected into the hot dry rocks. This is referred to as an engineered geothermal system. Northern Alberta is characterized by having low thermal gradient and geothermal energy is unsuitable for electricity production applications. However, it is applicable for direct heating, producing hot water for oil sands operations. Bitumen extraction in oil sands mining operations requires significant volumes of water at temperatures within the range of $50-60^{\circ} \mathrm{C}$. Critical environmental concerns are associated with these operations, including significant fresh water consumption and GHG emissions, in addition to concerns associated with the availability of the large volume of natural gas required. Geothermal energy provides the potential of mitigating two of these issues to significant extents (Gray et al., 2012).

The extraction of bitumen from oil sands requires significant volumes of hot water, which are provided by burning natural gas. Approximately $80 \%$ of oil sands reserves are located at great depths and require SAGD extraction methods, which mostly utilize steam in their operations. Geothermal energy has the potential to provide heat for bitumen extraction and upgrading operations, which would significantly reduce GHG emission levels. Geothermal 
resources are classified according to their subsurface temperatures as high $\left(>150^{\circ} \mathrm{C}\right)$, medium $\left(50-150^{\circ} \mathrm{C}\right)$ and low $\left(<50^{\circ} \mathrm{C}\right)$. Low temperature resources are found within the upper $2 \mathrm{~km}$ of the Western Canadian Sedimentary Basin, which are suitable for direct heating applications. Power generation using geothermal technologies requires very high temperatures $\left(>150^{\circ} \mathrm{C}\right)$, which to obtained requires drilling at great depths.

Majorowicz et al. conducted a research focused on evaluating potential heat sources that can be implemented for supporting oil sands operations in areas with existing leases. Their study was based on a detailed fracture modeling of the proposed geothermal system, in which they took into account the sensitivity of energy recovery to various well properties (e.g., fracture dimensions), the effect of reservoir temperatures and well spacing and sustained water flow rates and temperatures, and determined the optimal design of the EGS for the proposed location. The main area of interest for geothermal applications in the oil sands industry is located in the Athabasca region. The extraction of heat for power production applications would require the development of EGS. The heat is produced by circulating fluids at depths after creating artificial porosity zones. Temperatures greater than $80^{\circ} \mathrm{C}$ are typically required for EGS electricity production applications. High temperatures can be found in the deep Alberta basin within sedimentary aquifers and requires drilling to the depth of several kilometers. However, temperatures in Northern Alberta are considerably low to be suitable for electricity production and the main focus is to utilize geothermal resources to provide heat for oil sands operations (Gray et al., 2012).

Majorowicz et al. conducted an economic analysis of utilizing geothermal energy for heat and power production for oil sands operations in Alberta. For direct heating applications the calculations were done for drilling a well doublet up to $6 \mathrm{~km}$ in depth, in which the flow rate of water is sustained for 10 years and production temperature is maintained at $60^{\circ} \mathrm{C}$. At a sustained flowrate of $40-60 \mathrm{~L} / \mathrm{s}$ the cost of direct geothermal heating is similar to the cost range of burning natural gas $(\$ 3-6 / G)$ at $50 \%$ boiler efficiency). The results they obtained was used as input for the techno economic data of geothermal systems in the optimization model (Table 1). It was concluded from their results that direct geothermal heating is economic in comparison with burning natural gas considering expected future increases in natural gas prices and significant incurred carbon mitigation costs associated with the increasingly stringent environmental constraints. The total cost of burning natural gas to provide the same amount of hot water for oil sands operations costs approximately $\$ 0.012$ per kWh. Considering future increases in natural gas prices and added cost of mitigating the associated GHG emissions, it can be concluded that geothermal energy production has an economic advantage (Majorowicz et al., 2012). The utilization of geothermal heat for the production of electricity requires the use of an Organic Rankine Cycle, which is characterized with efficiency levels in the range of $8-12 \%$. For a system of one injection and two producing wells at a rate of $50 \mathrm{~L} / \mathrm{s}$ and temperatures in the range of $50-150{ }^{\circ} \mathrm{C}$ will require a cost of approximately $\$ 22$ million per MW. Great drilling depths will be required as the temperature gain with depth in crystalline rocks of the Athabasca region are considerably low. As a result electricity production from EGS for oil sands operations is considered uneconomic (Majorowicz et al., 2012; Pathak et al., 2013).

\subsubsection{Wind power-to-hydrogen via electrolysis}

The oil sands industry in Alberta is highly dependent on hydrogen for the upgrading of bitumen, for which the demand is expected to reach approximately 3.1 million tons per year by 2023. This translates to a significant projected increase in hydrogen requirement since hydrogen production for Canada as a whole was approximately 2 million tons per year in 2004. This in return will require an increased reliance on renewable alternatives in order to maintain or achieve higher GHG emission reduction levels. Hydrogen used for oil sands upgrading processes is mostly produced using steam methane reforming, which contributes significantly to increase in GHG emissions associated with oil sands operations. The production of hydrogen from wind energy can contribute to considerably reduce GHG emissions associated with bitumen upgrading operations (Alberta Electric System Operator, 2012).

Hydrogen production from renewable energy sources is considered the long-term goal for the hydrogen economy. Hydrogen production from wind energy via electrolysis has received global recognition as a potentially viable hydrogen production pathway among renewable resources. It is also considered to be one of the hydrogen production pathways that imposes the least environmental impacts based on life cycle assessment analysis studies. The production of hydrogen from wind energy has received little attention in Canada, and its employment is typically in conjunction with other renewable energy sources or a part of an energy mix. Other than utilization in the automobile industry, the production of hydrogen from renewable sources for other industrial sectors in Canada is rarely investigated (Bartholomy, 2005).

Alberta's installed wind capacity is currently determined to be $1434 \mathrm{MW}$, which accounts to approximately $9 \%$ of total electricity generation capacity, and is expected to increase by $58 \%$ by 2024 . There has been a considerable increase in installed wind capacity over the base decade by seven-fold, and considering the required abatement of GHG emissions the installed capacity of wind power is expected to further increase. Therefore, increasing utilization of wind power is an attractive solution to decrease reliance on fossilfuel based technologies for both power and hydrogen production, which will allow significant reductions in GHG emissions (Alberta Electric System Operator, 2012; Bartholomy, 2005).

Electrolysis of water is mature technology that generates hydrogen with very high purity (>99.9\%), which is highly desirable for bitumen upgrading operations to produce synthetic crude oil. The wind hydrogen plant incorporated in the proposed energy model is based on the expansion of an existing wind farm (i.e., Summerview wind farm) in Pincher Creek, Alberta. Currently the wind farm has an installed capacity of 134 MW. In 2010 the Summerview wind farm has undergone a capacity expansion where they approximately doubled their power production capacity, which was established in the Summerview 2 wind farm located adjacent to Summerview 1 . This provides plausibility for the further expansion of the wind farms to accommodate for the production of hydrogen given the entailed environmental benefits. A proposed expansion project of a wind hydrogen plant in such a location will reduce the cost of hydrogen production due to the eliminated costs of land purchase, grid connections, infrastructure, etc. This can facilitate a cost effective approach for hydrogen production.

Southern Alberta is the primary area with significant wind resources in the province, in which all wind farms of Alberta are currently allocated. The transmission infrastructure in this region requires significant improvements to transport wind power to large load centers. Therefore, the wind hydrogen plant will incorporate electrolyzers to be installed in conjunction with wind turbines at Pincher Creek, and the produced hydrogen is then transported to bitumen upgraders in Fort McMurray (Bartholomy, 2005).

Due to the variability of wind power resources, it is necessary to quantify the available wind energy potential by accounting for the average hourly wind speed variation in Pincher Creek (Fig. 1) (Government of Canada, 2014). A Vestas V-90 1.8 MW wind turbine is used for the wind hydrogen plant, which is the type of wind turbine currently used in the Summerview wind farm. The power curve for the selected wind turbine is shown in Fig. 1 (Sttaffel, 2012). The power characteristics of a wind turbine are defined in their associated power curve. These include cut-in and cut-out speeds, 
Table 1

Characteristics of a geothermal plant producing hot water for oil sands operations.

\begin{tabular}{ll}
\hline Geothermal system & One injection and two production wells \\
Temperature increase $\Delta T$ & $35^{\circ} \mathrm{C}$ \\
Water flowrate & $100 \mathrm{~kg} \mathrm{~s}^{-1}$ \\
Project lifetime & 30 year \\
Capital cost (i.e., drilling, fracturing, and pumps and surface installations) & $\$ 33$ million \\
Operating cost (i.e., pumping, water treatment, transportation, etc.) & $\$ 2 \mathrm{million}^{\mathrm{year}}{ }^{-1}$ \\
Total cost of EGS & $\$ 0.013$ per $\mathrm{kWh}^{\mathrm{h}}$ thermal
\end{tabular}
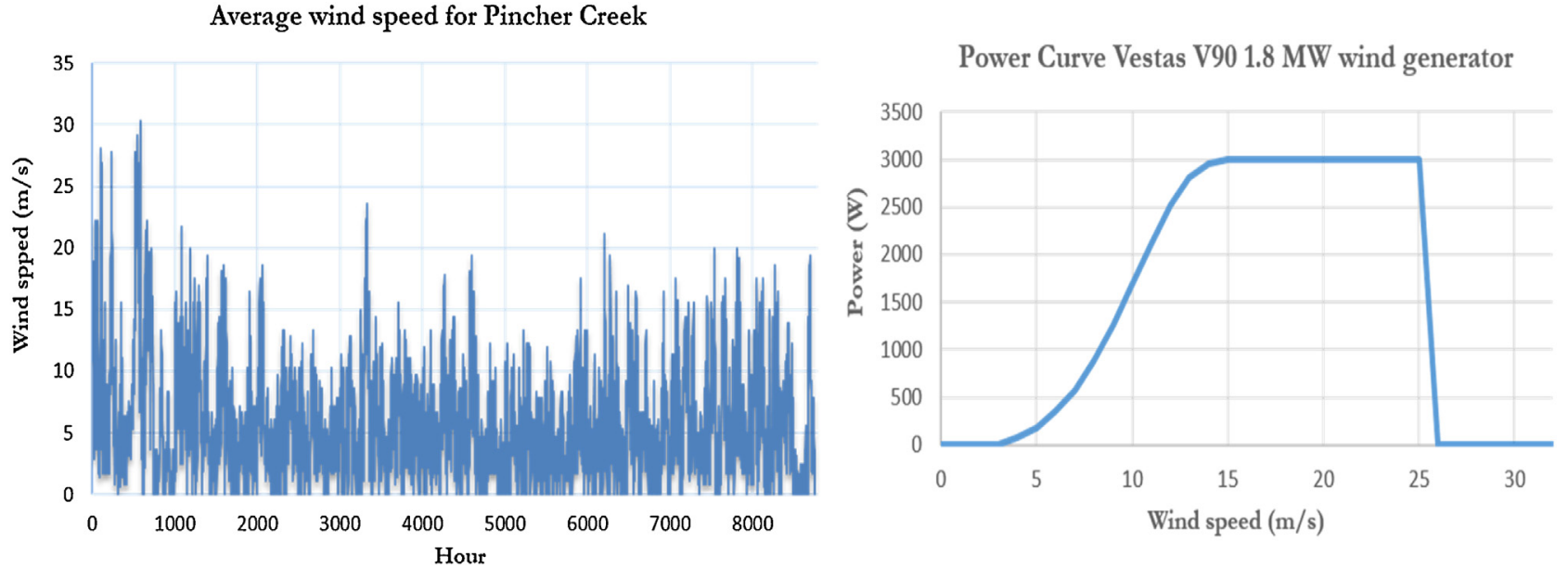

Fig. 1. Average wind speed data for Pincher Creek and power curve for Vestas V90 wind turbine.

rated power, efficiency and power coefficient. The power curve can be used to translate a certain wind speed to the amount of power that can be generated, and considering the variability of wind speed in a certain region the capacity factor of the wind turbine can be calculated. Using the wind speed data for Pincher Creek and the Vestas power curve the annual energy yield and capacity factor can be calculated using the methodology outlined in Olateju and Kumar (2011). They are determined to be 7.4 MWh and 46.7\%, respectively.

There are three main types of electrolyzers, which are alkaline, proton exchange membrane and high-temperature electrolyzers. The scale of hydrogen flow rate is one of the most important factors influencing the selection of a suitable type of electolyzer for the wind power-to-hydrogen plant application. This is affected by achieving economies of scale reducing the capital cost of hydrogen production with the increase in production capacity. Moreover, maximizing the capacity factor of an electrolyzer considerably decreases the unit cost of hydrogen production; however, the capacity factor is also affected by the relative size of the electrolyzer and the wind turbine. Alkaline electrolyzers are determined to be the most suitable for the considered application for their scale of hydrogen flow rate, efficiencies, and relatively low capital costs.

Olateju and Kumar (2011) and Olateji et al. (2014) conducted two studies on the techno-economic evaluation of electrolytic hydrogen production from wind energy for the upgrading operations of bitumen from oil sands. This system would have virtually no GHG emissions during operation. The wind-hydrogen plant they proposed has a capacity of $563 \mathrm{MW}$ with the delivery of hydrogen to the bitumen upgraders via pipeline. They assessed several plant configurations to determine the optimum electrolyzer size and quantity. The optimal plant configuration they obtained consists of 80 electrolyzers with a production capacity of $760 \mathrm{Nm}^{3} \mathrm{~h}^{-1}$ each and a hydrogen production cost of $\$ 8.43 \mathrm{~kg}^{-1}$.

Running electrolyzers strictly from wind electricity can result in annual capacity factor as low as 30\%, and in low wind electricity seasons the capacity factor of electrolyzers can be considerably lower ( $10 \%$ of high season). This requires significant amounts of hydrogen storage. Reducing hydrogen storage by relying on other sources of electricity production (e.g., fossil fuels, nuclear, biomass, etc.) will result in a considerably low capacity factors for these resources as well (Alberta Electric System Operator, 2012).

\subsubsection{Hydropower}

Oil sands operators are allowed to withdraw up to 441 million $\mathrm{m}^{3}$ of water from the Athabasca River annually, which is expected to increase by as much as $200 \%$ over the upcoming few years. In addition, there are no regulations on freshwater withdrawal by oil sands operators even during low-flow periods, which represent the highest threats for downstream ecosystems. Less than $5 \%$ of the withdrawn water is returned to the river, and most of it ends up in toxic tailing ponds. Annual runoff in the Athabasca River has considerably declined over the past few decades by up to $30 \%$, and a further $30 \%$ reduction in runoff is projected to occur in the future with the sustained water withdrawal. If the projected decline in river flowrates persist, then future water supplies may be insufficient to support future development of oil sands operations and sustain ecosystems (Canada's Rivers at Risk, 2012; HATCH, 2010). The river reach between Fort McMurray and Lake Athabasca was considered to have low potential for the development of hydropower applications due to several factors. These include flat gradient, low banks, wide valley, and the considerable water resources assigned for bitumen extraction operations. Even though hydropower has significant potential in reducing GHG emission, the potentially threatened river ecosystems hinder their development to support oil sands operations. Therefore, hydropower production is disregarded in the proposed optimization model (HATCH, 2010; Anon, 2014).

\subsubsection{Biomass}

Western Canada hosts significant amount of forest and agricultural residues remaining from logging operation by pulp and lumber industries. These residues are abandoned on roadsides where they rot and release GHG emissions to the atmosphere. Agri- 
cultural residues in Western Canada also include straw from wheat and barley crops. Utilizing these agricultural residues for energy production can allow achieving reductions in GHG emissions and reliance of fossil-fuel sources of energy. The pulp and timber industries are where most of whole-forest biomass is allocated, which makes it unavailable for bioenergy production. However, most of the residues remain unused, which can be allocated for energy production to support the oil sands operations. Utilizing biomass for the production of energy will reduce the intensity of GHG emissions associated with oil sands operations. The emissions from bioenergy production include emissions from the production processes, biomass transportation, plant construction, and energy commodity transportation (Sarkar and Kumar, 2010; Bradley, 2010).

Sarkar and Kumar (2010) investigated the feasibility of incorporating biohydrogen production from forest and agricultural residues for upgrading of bitumen from oil sands. On average, there is approximately 6.48 million dry tons year ${ }^{-1}$ of forest and agricultural residues for biohydrogen production, which can provide potential for reducing GHG emissions as well as dependence on hydrogen production from fossil fuels. They considered two types of gasifiers, which are the Battelle Columbus Laboratory (BCL) and the Gas Technology Institute gasifiers (GTI). The latter is more preferable for large-scale biohydrogen production. The optimal plant sizes for BCL and GTI gasification technologies were determined to be approximately 3000 dry tons day ${ }^{-1}$ and 6000 dry tons day ${ }^{-1}$, respectively. Both technologies were considered for the proposed energy optimization model (Kumarappan et al., 2009). Other options that were considered for the utilization of biomass as a source of fuel are for the production of SAGD steam using fluidized bed gasification boilers (EPA, 2010) and for power production (Black and Veatch, 2012). On average, there is approximately 6.48 million dry tons year ${ }^{-1}$ of forest and agricultural residues that could be utilized for producing energy for the oil sands industry (Sarkar and Kumar, 2010). The considered energy commodity producers that can utilize biomass as a fuel are biomass gasification boilers for the production of SAGD steam, biomass IGCC power plants, and biohydrogen gasification plants.

\section{Optimization model}

The methodology used for the optimized integration of renewable energy technologies into the oil sands energy infrastructure is outline in Fig. 2. After determining potentially viable renewable energy technologies that can provide adequate energy supply, techno-economic data about different energy commodity producers are used as an input to the optimization model. The energy requirements of oil producers for steam, electricity, hot water, hydrogen and process fuels should be balanced with supply of energy producers. Finally, the capacity expansion of conventional and renewable energy technologies is optimized using the developed model, which is the core of the methodology used to integrate renewable energy in the oil sands infrastructure.

This section presents the renewable energy and capacity expansion optimization model. The proposed model is used to select the optimal set of oil producers and quantify their energy requirements. Integrated extraction (SAGD or mining)/upgrading and SAGD extraction are considered for the production of SCO and commercial bitumen, respectively. Their energy requirements are supplied by power plants, hydrogen plants and steam boilers. Renewable energy technologies were also considered for power, hydrogen, steam and hot water production. Natural gas is also used in upgrading operations, and diesel is used to fuel trucks and shovels for mining operations. The model imposes $\mathrm{CO}_{2}$ emission constraints on the energy infrastructure, which are met by integrating carbon capture and sequestration (CCS) technologies and producing energy through renewable systems. Fig. 3 shows a schematic representation of the proposed energy optimization model. The optimization model is geared toward the minimization of the total cost (i.e., net present value) of producing energy, while being subject to energy commodity and oil producers' capacity, environmental, energy requirements and supply constraints.

\subsection{Energy commodity producers}

Energy commodity producers are included in the proposed model to provide the energy requirements for oil sands operations. The energy commodities considered include power, hydrogen, steam and hot water that can be produced by non-renewable and renewable energy technologies. The energy producers used to satisfy the energy requirements include boilers and geothermal energy for the production of SAGD steam, process steam and hot water. Power plants are used to satisfy the electricity requirements of oil sands extraction and bitumen upgrading processes. Hydrogen plants are used to satisfy the hydrogen demands of bitumen upgrading operations.

\subsubsection{Boilers}

The proposed model considers two types of boilers, which are conventional natural gas boilers and biomass-fired boilers. The boilers are also classified based on the type of steam they produce. A set of natural gas and biomass boilers are defined for the production SAGD steam, which produce $80 \%$ quality steam at $8000 \mathrm{kPa}$. The amount of SAGD steam $\left(\mathrm{SS}_{b}\right)$ produced from natural gas and biomass boilers is calculated as follows (Common Boiler Formulas, 2006):

$\mathrm{SS}_{b}=\frac{\mathrm{HHV}_{b} \eta_{b}}{\Delta \mathrm{HSS}} \mathrm{XB}_{b}$

where $\mathrm{HHV}_{b}$ is the heating value $\left(\mathrm{kJ} / \mathrm{Nm}^{3} \mathrm{NG}\right.$ or $\mathrm{kJ} /$ ton biomass) of the fuel used by boiler type $b, \Delta$ HSS is the change in enthalpy (kJ/ton steam), $\eta_{b}$ is the boiler efficiency, and $\mathrm{XB}_{b}$ is the amount of fuel consumed $\left(\mathrm{Nm}^{3}\right.$ of $\mathrm{NG} / \mathrm{h}$ or ton biomass/h).

Another type of steam considered in the optimization model is process steam, which is generated at $6300 \mathrm{kPa}$ and $500^{\circ} \mathrm{C}$. Process steam is used in the mining extraction process of bitumen and in the upgrading process of bitumen to produce synthetic crude oil. The amount of process steam produced can be calculated as follows:

$\mathrm{PS}_{b}=\frac{\mathrm{HHV}_{b} \eta_{b} \% S}{\Delta \mathrm{HPS}} \mathrm{XB}_{b}$

Hot water is also used in the mining extraction process of bitumen, and it is produced at $35^{\circ} \mathrm{C}$. In the proposed model it is assumed that hot water is coproduced in the boiler dedicated for the production of process steam. The amount of hot water produced can then be calculated as presented in Eq. (3), where \%S is the percentage of boiler capacity dedicated for the production of process steam.

$\mathrm{HW}_{b}=\frac{\mathrm{HHV}_{b} \eta_{b}(1-\% S)}{\Delta \mathrm{HHW}} \mathrm{XB}_{b}$

The number of new natural gas boilers $\left(\mathrm{NB}_{b}\right)$ installed and existing boilers $\left(\mathrm{ENB}_{b e}\right)$ must satisfy the total production requirements of SAGD steam $\left(\mathrm{SS}_{b}\right)$, process steam $\left(\mathrm{PS}_{b}\right)$ and hot water $\left(\mathrm{HW}_{b}\right)$. The maximum capacity of each boiler is defined by the parameter $S_{b}^{\max }$ (ton steam/h). The capacity constraints for SAGD steam, process steam and hot water boilers are defined by Eqs. (4)-(6).

$$
\begin{aligned}
& \mathrm{SS}_{b} \leq\left(\mathrm{NB}_{b}+\sum_{e \in E_{b}} \mathrm{ENB}_{b e}\right) S_{b}^{\max } \\
& \mathrm{PS}_{b} \leq\left(\mathrm{NB}_{b}+\sum_{e \in E_{b}} \mathrm{ENB}_{b e}\right) S_{b}^{\max \% S}
\end{aligned}
$$




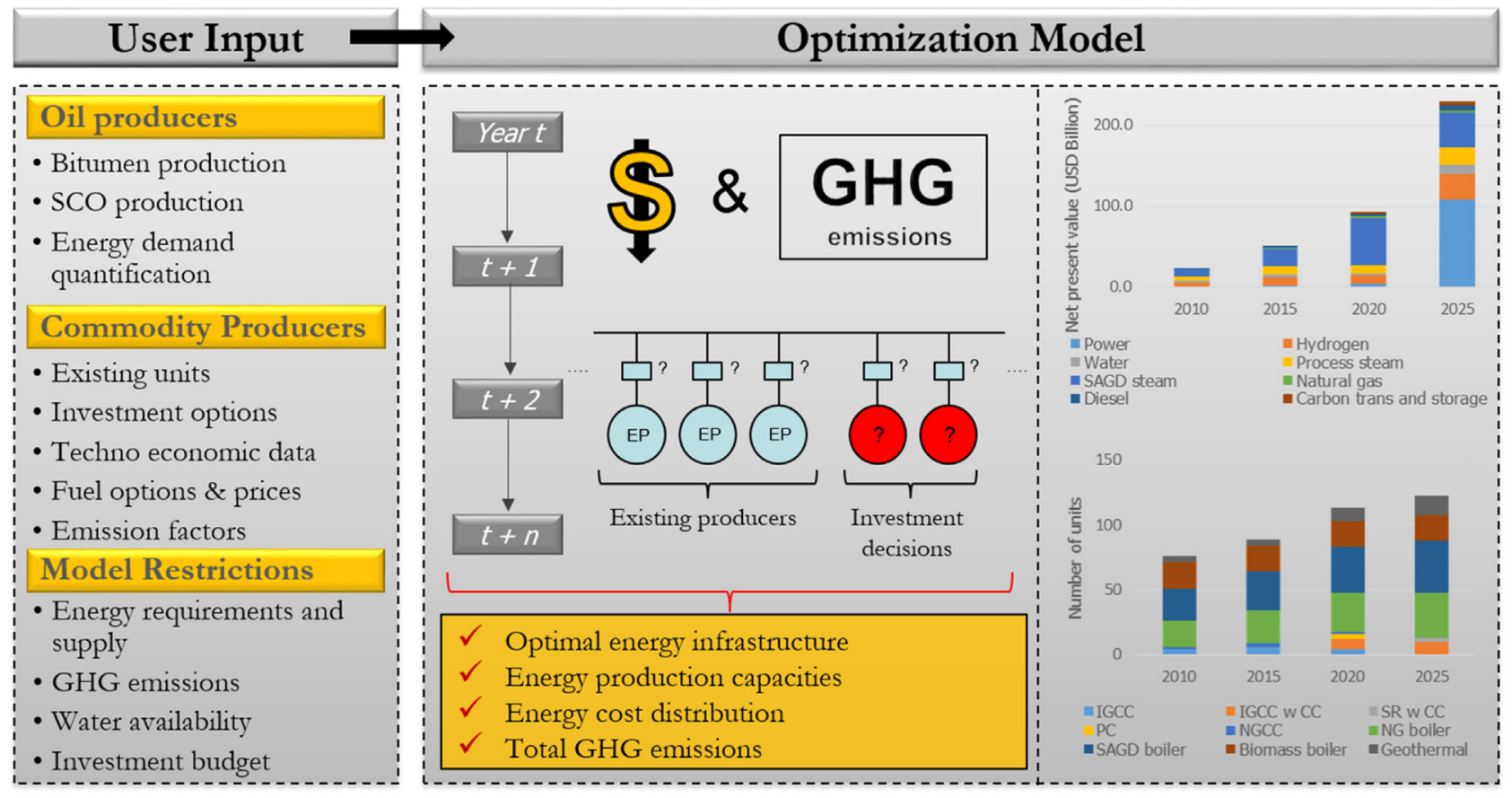

Fig. 2. General structure of the renewable energy capacity expansion optimization model.

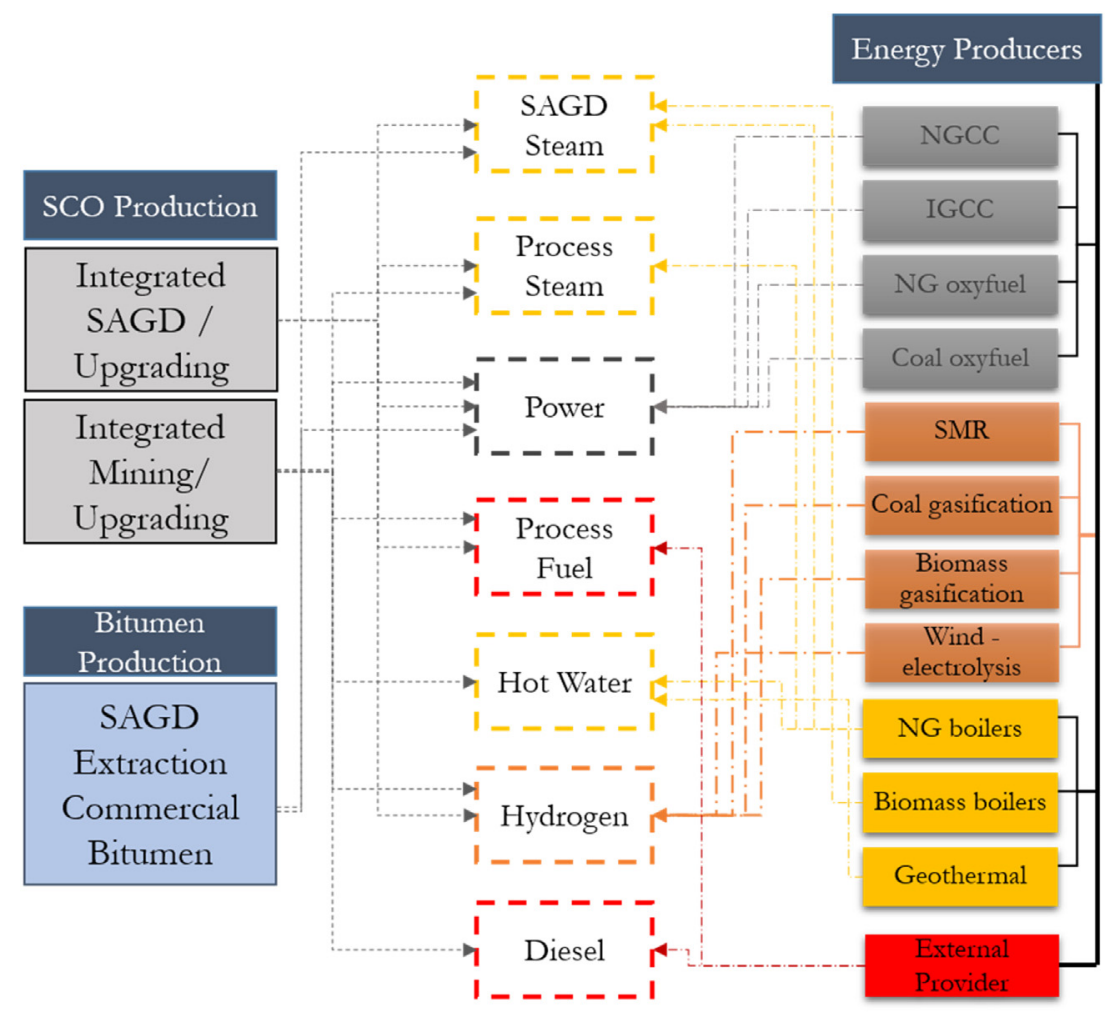

Fig. 3. Schematic presentation of the energy optimization model.

$\mathrm{HW}_{b} \leq\left(\mathrm{NB}_{b}+\sum_{e \in E_{b}} \mathrm{ENB}_{b e}\right) S_{b}^{\max }(1-\% S) \frac{\Delta \mathrm{HPS}}{\Delta \mathrm{HHW}}$

\subsubsection{Power plants}

The conventional power generation plants considered in the energy infrastructure are natural gas combined cycle (NGCC), oxyfuel, integrated gasification combined cycle (IGCC), and super- critical pulverized coal (SCPC) (Garcia-Cortes et al., 2009; Rubin et al., 2004). Natural gas is used as a feedstock in NGCC and oxyfuel plants. Coal is used as a feedstock in IGCC, SCPC and oxyfuel technologies. For each technology integration with carbon capture and sequestration was also considered. Biomass gasification was considered as a renewable option for the production of power (Black and Veatch, 2012). 
The production from natural gas and coal power plants can be modeled as presented in Eq. (7) (Demirel, 2012; International Energy Agency, 2010; National Energy Strategy, 1992), given the heating value of fuel utilized $\left(\mathrm{HHV}_{p}, \mathrm{NG}: \mathrm{kJ} / \mathrm{Nm}^{3}\right.$ or coal and biomass: $\mathrm{kJ} / \mathrm{kg})$ and the heating rate $\left(\mathrm{HR}_{p}, \mathrm{~kJ} / \mathrm{kW}\right)$ of power production technology $p$. The amount of power produced $\left(\mathrm{PP}_{p}\right)$ can then be calculated based on the amount of fuel consumed ( $\mathrm{FP}_{p}, \mathrm{NG:} \mathrm{Nm}^{3} / \mathrm{h}$ or coal and biomass: $\mathrm{kg} / \mathrm{h}$ ) as follows:

$\mathrm{PP}_{p}=\frac{\operatorname{HHV}_{p}}{\mathrm{HRP}_{p}} \mathrm{FP}_{p} \forall p$

The capacity constraint for each power production technology $p$ is defined in Eq. (8). The amount of power produced $\left(\mathrm{PP}_{p}\right)$ must be less than or equal to the maximum capacity of technology $p\left(\mathrm{PP}_{p}^{\max }\right)$ multiplied by the number of new $\left(\mathrm{NP}_{p}\right)$ and existing $\left(\mathrm{ENP}_{p e}\right)$ units selected by the optimization model.

$\mathrm{PP}_{b} \leq\left(\mathrm{NP}_{b}+\sum_{e \in E_{p}} \mathrm{ENB}_{p e}\right) \mathrm{PP}_{p}^{\max } \forall p$

\subsubsection{Hydrogen plants}

Steam methane reforming and coal gasification (Simbeck and Chang, 2002; Simbeck, 2004; Chiesa et al., 2005) are the two conventional hydrogen production technologies considered within the energy infrastructure for the oil sands operations. Biomass gasification is also considered as a renewable hydrogen production technology. For each type of fossil-fuel based hydrogen production plant integration with carbon capture and sequestration was also considered. The amount of hydrogen produced by each technology can be modeled based on Eq. (9) (Jechura, 2015; Maxwell, 2004), given the heating value $\left(\mathrm{HHV}_{h}, \mathrm{NG}: \mathrm{kJ} / \mathrm{Nm}^{3}\right.$ or coal and biomass: $\mathrm{kJ} / \mathrm{kg}$ ) of the fuel utilized and the heating rate required to produce one ton of hydrogen $\left(\mathrm{HRH}_{h}, \mathrm{~kJ} /\right.$ ton $\left.\mathrm{H}_{2}\right)$ for each hydrogen production technology $h$. The amount of hydrogen produced can then be calculated based on the amount of fuel consumed $\left(\mathrm{FH}_{h}, \mathrm{NG}: \mathrm{Nm}^{3} / \mathrm{h}\right.$ or coal and biomass: $\mathrm{kg} / \mathrm{h}$ ).

$\mathrm{HH}_{h}=\frac{\mathrm{HHV}_{h}}{\mathrm{HRH}_{h}} \mathrm{FH}_{h} \forall h$

Coal gasification hydrogen production plants are used to cogenerate electricity. Part of the synthetic gas that is produced from the gasification process is used to drive gas turbines for power generation. Cogeneration can be incorporated in the oil sands energy infrastructure as an option to increase energy efficiency. It is therefore necessary to quantify the net power $\left(\mathrm{PH}_{h}\right)$ required or produced by these technologies, which is assumed to be a factor $\left(\mathrm{HP}_{h}^{\text {cogen }}, \mathrm{kWh} /\right.$ ton $\left.\mathrm{H}_{2}\right)$ of the amount of hydrogen produced $\left(\mathrm{HH}_{h}\right)$ by technology $h$. This can be presented as follows:

$\mathrm{PH}_{h}=\mathrm{HP}_{h}^{\text {cogen }} \mathrm{HH}_{h} \forall h$

The capacity constraint for each hydrogen production technology $h$ can be defined as illustrated in Eq. (11). The maximum capacity for technology $h$ is defined by the parameter $\mathrm{HH}_{h}^{\max }$ (ton $\mathrm{H}_{2} / \mathrm{h}$ ). The total amount of hydrogen produced by technology $h$ $\left(\mathrm{HH}_{h}\right)$ must be satisfied by the total number of newly installed $\left(\mathrm{NH}_{h}\right)$ and existing plants $\left(\mathrm{ENH}_{h e}\right)$.

$\mathrm{HH}_{h} \leq\left(\mathrm{NH}_{h}+\sum_{e \in E_{h}} \mathrm{ENB}_{h e}\right) \mathrm{HH}_{h}^{\max } \forall h$

\subsubsection{Geothermal}

The geothermal heating system used in the proposed optimization model is based on the results obtained by Pathak et al. (2013). They determined that the optimum geothermal direct heating system is composed of three wells (one injector and two producers) with a horizontal spacing of 500-600 m. Compared to other systems this arrangement provided improved heat transfer due to the increase in contact between injected water and the hot dry rocks. Such a system is capable of providing a thermal power output as high as 29.4 MW (Pathak et al., 2013).

The geothermal heating system is most suitable to provide the heating requirements for hot water production used in oil sands mining operations (Pathak et al., 2013). The amount of hot water produced from geothermal heating $(\mathrm{GW}$, ton/h) can be calculated as the ratio of the heating rate (HRGEO, $\mathrm{MJ} / \mathrm{h}$ ) of the geothermal system to the change in enthalpy of water ( $\triangle \mathrm{HHW}, \mathrm{MJ} /$ ton $)$, and can be presented as follows:

$\mathrm{GW}=\frac{\text { HRGEO }}{\Delta \mathrm{HHW}}$

The total amount of hot water production (GW) must be less than or equal to the maximum capacity of a geothermal system (HRGEO $^{\max } / \Delta \mathrm{HHW} \mathrm{MJ} \mathrm{h}^{-1} / \mathrm{MJ} \mathrm{ton}^{-1}$ ) multiplied by the number of new (NGEO) and existing $\left(\mathrm{EGEO}_{e}\right)$ units selected by the optimization model. The capacity constraint can be presented as follows:

$\mathrm{GW} \leq\left(\mathrm{NGEO}+\sum_{e \in E_{\mathrm{GEO}}} \mathrm{EGOE}_{e}\right) \frac{\mathrm{HRGEO}^{\mathrm{max}}}{\Delta \mathrm{HHW}}$

\subsubsection{Wind power-to-hydrogen via electrolysis}

Olateju and Kumar (2011) and Olateji et al. (2014) investigated the feasibility of integrating various electrolyzer capacities that can be integrated with wind power. According to their results the optimum size of the electrolyzer in the wind power-to-hydrogen plant is $3496 \mathrm{~kW}$. This is the capacity of the electrolyzer considered in the proposed optimization model. The electrolyzer will utilize power from the Vestas V-90 1.8 MW turbines considered in this model, which is the type of turbine used in the Summerview wind farm in southern Alberta.

Power production from the wind turbines must satisfy the power requirements of the electrolyzers. The power produced from a wind turbine can be estimated by the product of its annual power yield (AWP, kW) and its capacity factor (WTCF). These were estimated by the methodology outlined by Olateju and Kumar (2011) and Olateji et al. (2014) based on the wind data available the Summerview wind farm in Southern Alberta (Government of Canada, 2014), and were determined to be $7400 \mathrm{kWh}$ and $46.7 \%$, respectively. The total amount of power produced from the wind turbines can be estimated by multiplying the power yield of a turbine multiplied by the number of newly installed (NWT) and existing $\left(\mathrm{EWT}_{e}\right)$ units selected by the optimization model, which can be represented as follows:

$\mathrm{PWT}=\left(\mathrm{NWT}+\sum_{e \in E_{\mathrm{WT}}} \mathrm{EWT}_{e}\right) \mathrm{WTCF}$ AWP

The yield of hydrogen from water electrolysis $\left(\mathrm{EER}^{-1}\right)$ is assumed to be 0.018 ton $\mathrm{H}_{2} / \mathrm{MWh}$ (Olateji et al., 2014). The total amount of hydrogen produced from newly installed and existing electrolyzers can therefore be calculated as follows:

$\mathrm{HHE}=\mathrm{PWT}^{\mathrm{E}} \mathrm{ER}^{-1}$

The number of electrolyzers selected depends on the maximum $\left(\mathrm{HH}_{\text {elect }}^{\mathrm{max}}\right)$ allowable hydrogen flowrates produced. Eq. (16) presents the capacity constraint for newly installed and existing electrolyzers. $\mathrm{NHE}_{\text {elect }}$ is an integer variable representing the number of new electrolyzers selected by the optimization model during a certain time period. ENHE $_{\text {elec }}$ is a binary variable that determines whether 
an existing electrolyzer is operational during the investigated time period (i.e., 1 if the electrolyzer is operational or 0 otherwise).

$\mathrm{HHE} \leq\left(\mathrm{NHE}+\sum_{e \in E_{\text {elec }}} \mathrm{ENHE}_{e}\right) \mathrm{HH}_{\text {elect }}^{\max }$

\subsection{Energy requirements}

The calculation of energy demands for oil sands operations depends on the extraction method, as well as the upgrading route of bitumen to produce synthetic crude oil. The two extraction methods considered are oil sands mining and steam assisted gravity drainage (SAGD). The bitumen produced from the extraction processes is then upgraded to synthetic crude oil. The production schemes incorporated in the optimization model are integrated mining/upgrading, integrated SAGD/upgrading, and standalone SAGD extraction for the production of commercial diluted bitumen. The upgrading route can be based on a thermocracking process (delayed coking and hydrotreatment), a hydrocracking process (LCfining and hydrotreatment), or a combination of both (LC-fining, fluid coking and hydrotreatment). All these stages require energy in the form of power, hydrogen, steam, heat and fuel (i.e., natural gas and diesel). The quantification of these energy demands is explained in details in the following sections. The procedure used to model the energy requirements for the considered oil sands operations is based on the approach developed by Ordorica-Garcia et al. (2007).

\subsubsection{Bitumen extraction}

Oil sands that are within $75 \mathrm{~m}$ from the surface are recoverable through mining operations. However, deeper deposits are only recoverable through in-situ extraction methods. In the proposed optimization model, it is assumed that only in-situ extraction methods are suitable for the production of commercial bitumen, whereas SCO can be produced through both integrated mining/upgrading and integrated SAGD/upgrading production schemes. The bitumen produced through mining operations typically contains high levels of solids and water, and therefore, it is usually upgraded to SCO on site instead of being marketed as it is unsuitable for shipping to conventional refineries.

2.2.1.1. Mining extraction. Mining extraction is a surface method used for the production of bitumen from oil sands. The energy commodities used in mining extraction operations are diesel, electricity, process steam and hot water. An energy resource that is extensively used in mining extraction is diesel. It is consumed by trucks and shovels used in mining operations. Diesel consumption depends on the specifications of the vehicles used and their number. A parameter is used to quantify the amount of diesel consumed per barrel of bitumen produced (MDC $=0.17 \mathrm{~L}$ diesel/bbl bitumen), which is based on a model of a typical Canadian Oil Sands mining operation (Ordorica-Garcia et al., 2007). The total amount of diesel consumed can be estimated from the amount of bitumen produced in the mining production routes as illustrated in Eq. (17), where $\mathrm{BIT}_{m}$ is the amount of bitumen produced through integrated mining/upgrading route $m$, and IMBIT $_{m}$ representing the selection of route $m$.

$\operatorname{MEDD}=\operatorname{MDC}\left(\sum_{m} \operatorname{IMBIT}_{m} \mathrm{BIT}_{m}\right)$

The electricity demand for mining operations can be calculated as illustrated in Eq. (18). The power used is mostly required for driving pumps, and the pumping factors are adopted from Ordorica-Garcia et al. (2007), which were determine based on simulations conducted in Aspen Plus. The power demand for hydrotransport depends on the slurry rate in tons per year $\left(\mathrm{SL}_{m}\right)$, the distance from the mine to the extraction plant in meters $d_{m}$, and a pumping factor $\mathrm{PF}_{m}(0.0787 \mathrm{kWh} /$ ton slurry $/ \mathrm{m})$ that indicates the power requirements necessary to transfer oil slurry into the following stage (Ordorica-Garcia et al., 2007).

The power demand for bitumen recovery is associated with the transportation of tailings and centrifugation stages. TPE $m$ and $\mathrm{TSE}_{m}$ are the tailings produced from primary and secondary extraction stages, respectively. The distance in meters between the extraction plant and the tailing ponds is defined by $\mathrm{dT}_{m}$. The electricity requirement is defined by the pumping factor $\mathrm{PFT}_{m}$ $(0.0016 \mathrm{kWh} / \mathrm{ton} / \mathrm{m})$ (Ordorica-Garcia et al., 2007). The amount of diluted bitumen transferred to the centrifugation stages is defined as $\mathrm{DBC}_{m}\left(\mathrm{~m}^{3} / \mathrm{h}\right)$ and ECR is the power requirement for centrifugation $\left(\mathrm{kWh} / \mathrm{m}^{3}\right)$.

$\mathrm{MEPD}=\sum_{m}\left(\mathrm{SL}_{m} d_{m} \mathrm{PF}_{m}+\left(\mathrm{TPE}_{m}+\mathrm{TSE}_{m}\right) \mathrm{dT}_{m} \mathrm{PFT}_{m}+\mathrm{DBC}_{m} \mathrm{ECR}\right) \mathrm{IMBIT}_{m}$

Process steam is required for conditioning and bitumen recovery stages. The amount of process steam can be calculated as presented in Eq. (19). $\mathrm{MO}_{m}$ is the oil sands mining rate (ton oil sand/hr) and $\mathrm{SC}_{m}$ is the steam requirement for the conditioning stage ( 0.036 ton steam/ton oil sand (Meyers, 1984)). Some of the mining production routes $m$ do not incorporate a conditioning stage, therefore, the parameter $\mathrm{SC}_{m}$ takes the value of zero in these routes. $\mathrm{BMF}_{m}$ is the bitumen froth produced in primary extraction (ton froth/hr) and SF is the steam requirement in bitumen extraction ( 0.04 ton steam/ton froth) (Meyers, 1984).

$\mathrm{MEPSD}=\sum_{m}\left(\mathrm{SC}_{m} \mathrm{MO}_{m}+\mathrm{SF} \mathrm{BMF}_{m}\right) \operatorname{IMBIT}_{m}$

The hot water demand for mining operations includes consumption in the conditioning, hydrotransport and bitumen recovery stages. Eq. (20) illustrates the calculation of the total water demand for mining operations. The water requirements for these stages are defined by the parameters $W_{m}$ ( 0.333 ton water/ton oil sand and zero for route $m$ that does not include a conditioning stage), $\mathrm{WH}$ ( 0.30 ton water/ton oil sand) and WR ( 0.41 ton water/ton oil sand extraction wash water requirement), respectively (Meyers, 1984).

$\mathrm{MEWD}=\sum_{m}\left(\mathrm{WC}_{m}+\mathrm{WH}+\mathrm{WR}\right) \mathrm{MO}_{m} \mathrm{IMBIT}_{m}$

2.2.1.2. SAGD extraction. The two energy commodities required for SAGD extraction operations are steam and electricity. The demand for SAGD steam (SSD) can be calculated as illustrated in Eq. (21). The SOR is the steam to oil ratio parameter, which is assumed to be 2.4 tons of steam per ton of bitumen extracted (OTPI Canada, 2002). The amount of commercial crude bitumen extracted is presented by the term CB (ton bitumen $\mathrm{h}^{-1}$ ), and $\mathrm{BIT}_{S}$ is the amount of bitumen considered for SCO production by each considered route $(s)$.

$\mathrm{SESD}=\operatorname{SOR}\left(\mathrm{CB}+\sum_{s} \operatorname{ISBIT}_{s} \mathrm{BIT}_{s}\right)$

The power required for the production of commercial bitumen and bitumen used for the production of SCO through integrated SAGD/upgrading operations can be calculated as presented in Eq. (22). ECB is a parameter that represents the electricity requirement for the production of bitumen by SAGD extraction $(3.1 \mathrm{~kW} /$ ton bitumen) (OTPI Canada, 2002).

$\mathrm{SEPD}=\mathrm{ECB}\left(\mathrm{CB}+\sum_{s} \mathrm{BIT}_{s} \mathrm{ISBIT}_{S}\right)$

\subsubsection{Upgrading operations}

Energy is required for the upgrading stages that are integrated with SAGD and mining extraction processes in order to convert the bitumen extracted to synthetic crude oil (SCO). There are three upgrading routes that are considered in the presented model, and each of them can be integrated with the mining or SAGD extraction methods. The three upgrading routes considered are: (1) LC-fining 
and hydrotreatment; (2) delayed coking and hydrotreatment; (3) LC-fining, fluid coking and hydrotreatment. LC-fining is a hydrocracking based process, and delayed coking and fluid coking are thermocracking based processes. There are significant amounts of energy required for these upgrading processes. The energy consumed is in the form of hydrogen, electricity, process steam, and process fuel (i.e., natural gas) for heating.

The first step in all upgrading routes is the diluent recovery unit (DRU), which involves the recovery of the diluent (i.e., naphtha) used to dilute the crude bitumen to facilitate its transportation by pipelines. The products generated in the first stage are naphtha, light gas oil (LGO), and atmospheric topped bitumen (ATB). The naptha is recycled, and the LGO and ATB are sent for further treatment to produce SCO.

The LGO is transferred to the hydrotreatment unit for sulfur and nitrogen removal. The ATB is sent to the vacuum distillation unit (VDU), or is split between the VDU and the LC-finer unit. LGO and heavy gas oil (HGO) are products from the VDU, which are sent to the hydrotreatment unit. The second upgrading stage involves mixing the bottom products of the VDU, which is known as the vacuum topped bitumen (VTB), with any residual ATB generated from the DRU. The mixture is then sent to LC-finers or delayed cokers. In delayed cokers the heavy hydrocarbons are cracked to lighter compounds using thermal energy, whereas in LC-finers they are cracked using hydrogen. There are two types of LC-finers considered in the proposed model, which are low and high conversion. The products from LC-finers and delayed cokers, which include LGO, HGO and naphtha are treated with hydrogen for the removal of impurities. For the low conversion LC-finers, the bottom products are further treated in fluid cokers to yield additional light hydrocarbons. The products remaining from the final upgrading stages are SCO from hydrotreatment and petcoke residue from LC-finers and cokers.

The upgrading units (i.e., LC-finers, cokers and hydrotreatment) included in the proposed model are modeled according to the approaches proposed in Meyers (1984), OTPI Canada (2002), Yui and Chung (2001), Anon (2004), Sunderland (2001), Schumacher (1982) and Van Driesen et al. (1979). The parameter representing the power, hydrogen and thermal (i.e., process steam and fuel) requirements of bitumen upgrading operations were obtained from these studies.

2.2.2.1. Power demand. The power demand for the upgrading stages can be quantified as presented in Eq. (23). $\mathrm{VTB}_{o}$ represents the amount of vacuum topped bitumen sent to the LC-finers or delayed cokers in the hydrocracking and thermocracking routes, respectively. For the upgrading route of LC-fining plus fluid coking an additional stream is sent to the LC-fining unit, which is a fraction of the atmospheric topped bitumen $\left(\mathrm{ATBF}_{o}\right)$. For this upgrading route the bottom oil from the LC-fining is sent to the fluid coker, which is presented by the variable $\mathrm{BF}_{0}$. The power requirement of the LC-fining for each upgrading route is presented by the parameter $\mathrm{EL}_{0}$, which is $23.3 \mathrm{kWh} /$ ton, $99.8 \mathrm{kWh} /$ ton for the delayed coker and LC-finer, respectively (Meyers, 1984; Yui and Chung, 2001). The power requirement of the fluid coker is presented by the parameter $\mathrm{ED}_{o}$, which is $36.3 \mathrm{kWh} / \mathrm{ton}$ (Anon, 2004).

$\mathrm{UPD}=\sum_{o \in(S \cup M)} \mathrm{EL}_{o}\left(\mathrm{VTB}_{o}+\mathrm{ATBF}_{o}\right)+\mathrm{ED}_{o} \mathrm{BF}_{o}$

2.2.2.2. Process steam demand. Process steam is required for diluent recovery, vacuum distillation and fluid coking. The total process steam demand for bitumen upgrading can be calculated as illustrated in Eq. (24). DR is the parameter that defines the fraction of diluent, and SRD ( 0.30 ton steam/ton feed) is the steam requirement for the DRU. The steam requirement in the VDU is presented by the parameter SRV ( 0.07 ton steam/ton feed) (Yui and Chung,
2001), and the ATB recovered from the DRU that is transferred to the VDU is presented by the variable $\mathrm{ATB}_{0}$ (ton/h), which excludes the fraction of ATB that is sent to the low conversion LC-finers $\left(\mathrm{ATBF}_{0}\right.$, ton/h). The steam requirement for the fluid coker unit is SRF ( 0.308 ton steam/ton feed (Yui and Chung, 2001)) and the amount of bottom oil from the LC-finer sent to the fluid coker is $\mathrm{BF}_{o}$ (ton/h).

$\mathrm{UPSD}=\sum_{o \in(\mathrm{S} \cup M)} \mathrm{BIT}_{o}(1+\mathrm{DR}) \mathrm{SRD}+\left(\mathrm{ATB}_{o}-\mathrm{ATBF}_{o}\right) \mathrm{SRV}+\mathrm{BF}_{o} \mathrm{SRF}$

2.2.2.3. Hydrogen demand. The total hydrogen demand for the upgrading stages in integrated SAGD/upgrading and mining/upgrading operations is calculated as illustrated in Eq. (25). Hydrogen is consumed in two stages, which are hydrocracking and hydrotreatment. The hydrogen requirement for hydrocracking is defined by the parameter $\mathrm{HRU}_{0}$. For the hydrocracking based route the hydrogen requirements for the LC-finer is $0.020 \mathrm{~kg}$ $\mathrm{H}_{2}$ /ton feed (Sunderland, 2001; Schumacher, 1982; Van Driesen et al., 1979). For the LC-finer plus fluid coking upgrading route, the hydrogen requirement of the LC-finer is $0.014 \mathrm{~kg} \mathrm{H}_{2} /$ ton feed (Meyers, 1984). The hydrogen requirements for the hydrotreatment of naphtha, LGO and HGO are presented by the parameters $\mathrm{HN}$ (0.0185 ton $\mathrm{H}_{2}$ /ton naphtha), $\mathrm{HL}$ (0.0186 ton $\mathrm{H}_{2}$ /ton LGO) and HHG (0.0175 ton $\mathrm{H}_{2}$ /ton HGO), respectively (Yui and Chung, 2001; Sunderland, 2001).

$$
\begin{aligned}
& \mathrm{UHD}=\sum_{o \in(\mathrm{S} \cup M)} \mathrm{HRU}_{o}\left(\mathrm{VTB}_{o}+\mathrm{ATBF}_{o}\right)+\mathrm{HN} N_{o}+\mathrm{HLG} \mathrm{LGO}_{o} \\
& +\mathrm{HHG} \mathrm{HGO}_{o}
\end{aligned}
$$

2.2.2.4. Fuel demand. The total requirement of natural gas for oil sands upgrading operations can be calculated as shown in Eq. (26). Natural gas is required for operating both hydrocracking (LC-fining) and thermocracking (delayed coking) based upgrading routes. The natural gas fuel requirements for LC-fining and delayed coking is presented by the parameter $F R_{o}$ (LC-fining: $0.562 \mathrm{GJ} /$ ton; delayed coking: $0.911 \mathrm{GJ} /$ ton) (Anon, 2004), where $o$ is the sub index representing the integrated mining or SAGD/upgrading route. HNG represents the heating value of natural gas $\left(0.038 \mathrm{GJ} / \mathrm{Nm}^{3}\right)$.

$\mathrm{UFD}=\frac{1}{\mathrm{HNG}} \sum_{o \in(\mathrm{S} \cup M)}\left(\mathrm{VTB}_{o}+\mathrm{ATBF}_{o}\right) \mathrm{FR}_{o}$

\subsubsection{Additional energy requirements}

The hydrogen production technologies have electricity requirements to drive pumps and compressors. Power is required for the operation of steam methane reforming plants that are utilized for hydrogen production. This energy requirement (SMPRD) can be calculated as illustrated in Eq. (27), where ESMR represents the electricity requirement $\left(\mathrm{kW} /\right.$ ton $\left.\mathrm{H}_{2}\right)$.

$\mathrm{SMRPD}=\mathrm{HH}_{\mathrm{SMR}} \mathrm{ESMR}$

Power consumption takes place during the transportation of $\mathrm{CO}_{2}$ to sequestration sites, which is calculated as illustrated in Eq. (28). $C_{i}$ (ton $\mathrm{CO}_{2} / \mathrm{h}$ ) represents the amount of $\mathrm{CO}_{2}$ captured in power and hydrogen plants, $\mathrm{ECC}_{i}\left(1.34 \mathrm{kWh} /\right.$ ton $\left.\mathrm{CO}_{2} / \mathrm{km}\right)$ is the electricity requirement for compressing $\mathrm{CO}_{2}$ for transport, and $L(\mathrm{~km})$ is the length of the $\mathrm{CO}_{2}$ pipeline connecting Fort McMurray and the depleted oil fields located near Edmonton, which is approximately $600 \mathrm{~km}$ (Betancourt-Torcat et al., 2011). The sub index $i$ represents the set of energy producers and commodities that are incorporated 
Table 2

Oil and energy producers considered in the optimization model.

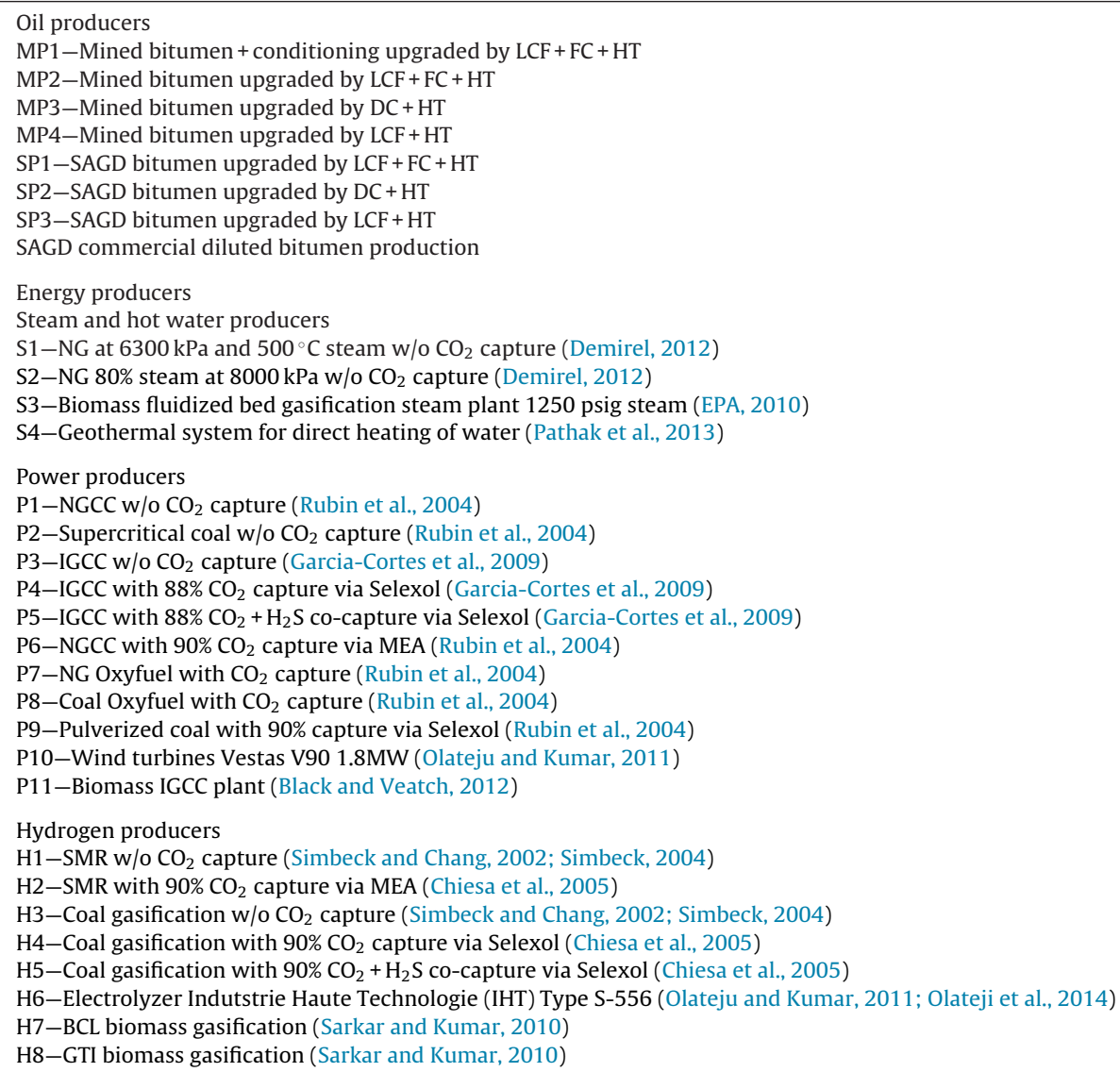

in the oil sands optimization model, which include power plants, hydrogen plants, steam and hot water producers, diesel and natural gas.

$\mathrm{CCPD}=\sum_{i \in(P \cup H)} C_{i} \mathrm{ECC}_{i} L$

\subsection{Environmental restrictions}

The $\mathrm{CO}_{2}$ emissions associated with energy commodity producers is determined by multiplying the $\mathrm{CO}_{2}$ emission factor (Table 3 ) of each producer by its total production capacity. As shown in Eq. (29) the total $\mathrm{CO}_{2}$ emissions (ton $\mathrm{CO}_{2} / \mathrm{h}$ ) associated with energy production for the oil sands industry can be calculated as the sum of emissions of energy producers $\left(\mathrm{CO}_{2} e_{i}\right)$.

$\mathrm{CO}_{2} \mathrm{~T}=\sum_{i} \mathrm{CO}_{2} e_{i}$

The $\mathrm{CO}_{2}$ emission constraint incorporated in the model is shown in Eq. (30). The $\mathrm{CO}_{2}$ emission target is set by the right hand side of the inequality equation. $\mathrm{CO}_{2} \mathrm{E}$ (ton/h) is an input parameter to the model the maximum allowable emission level for a certain operational year, and the \%RED is a parameter that indicates the percentage emissions reduction that is required to be achieved.

$\mathrm{CO}_{2} \mathrm{~T} \leq \mathrm{CO}_{2} E(1-\% \mathrm{RED})$

\subsection{Objective function}

The NPV is used to facilitate incorporation of capacity expansion decisions. This facilitates the comparison between existing and newly established facilities. The annuity costs $(A)$ are converted to NPV by using the following general formula:

$\mathrm{NPV}=A \mathrm{PVF}$

The present value annuity factor $(P V F)$ is defined by the following formula:

$\mathrm{PVF}=\frac{1-(1+i)^{-(L-\Delta T)}}{i}$

where $i$ is the annual interest rate, which is assumed to be $15 \%$. $L$ is the life of plant for which the NPV is calculated. $\Delta T$ is the time difference between the current year of operation and the year at which the plant was established.

The individual cost of each commodity is calculated by multiplying the number of newly established and existing units of each commodity producer by the capital and operating cost factors associated with each technology. The capital cost factors represent the amortized investment cost over the plants operating lives. The total cost of commodity production also depends on the fuel (i.e., natural gas, coal, etc.) consumption and the price of fuel. The production costs of power, hydrogen, steam and hot water are represented as follows.

\subsubsection{Power cost}

The net present value of the cost of power production (PC, \$) can be calculated as illustrated in Eq. (33). $\mathrm{NP}_{p}$ is an integer variable that indicates the number of new plants installed from each power production technology. $\mathrm{EP}_{p e}$ is a binary variable that indicates whether or not an existing plant is operational during an investigated year. $\mathrm{CCP}_{p}$ (\$/year) and $\mathrm{OMP}_{p}$ (\$/year) are the amortized capital cost and operating and maintenance cost factors, respectively, for each 
Table 3

Techno-economic parameters of energy producers.

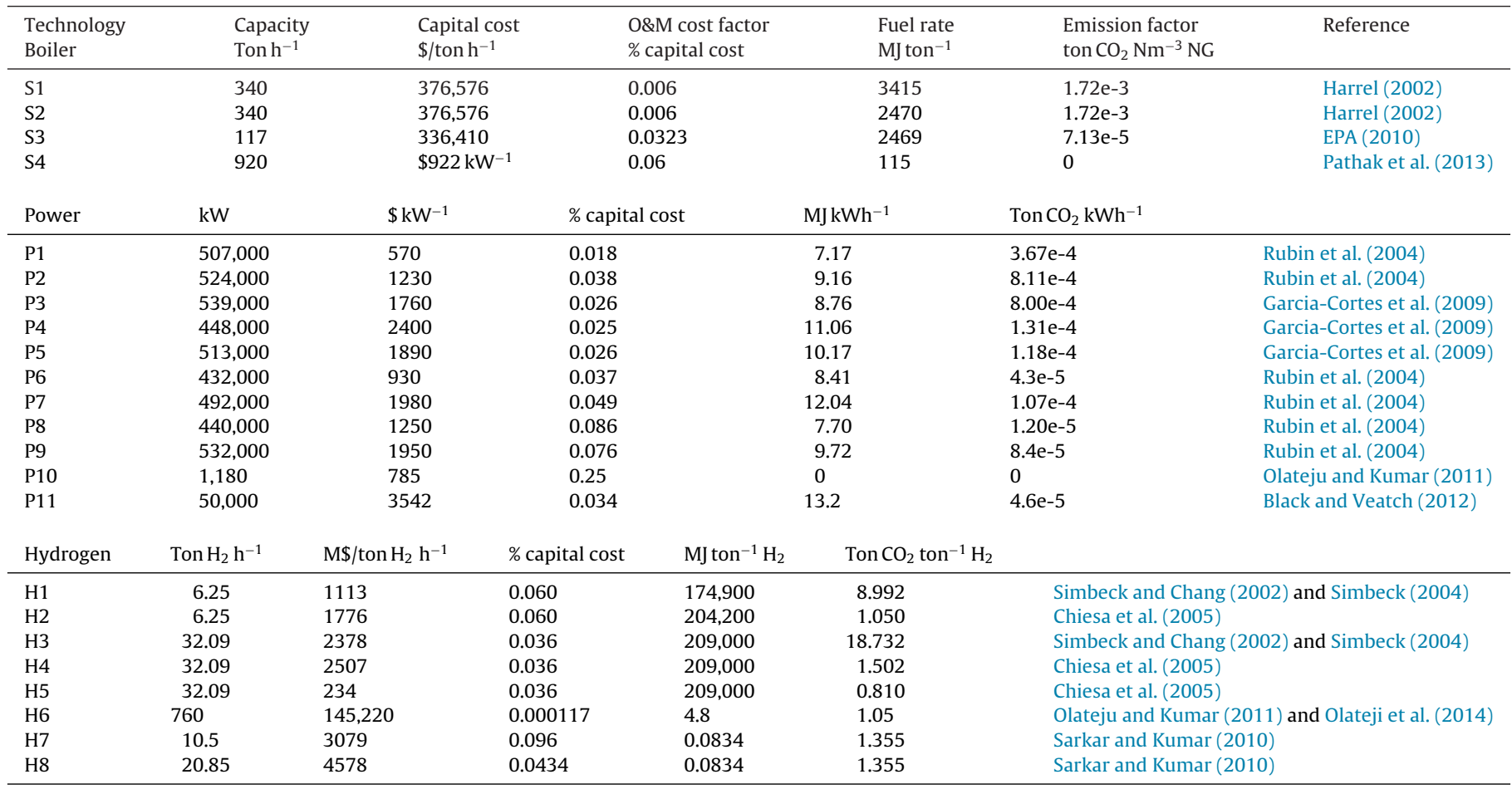

power production technology $p . \mathrm{FP}_{p}(\mathrm{GJ} / \mathrm{h})$ is the amount of fuel consumed by production technology $p$, and $\mathrm{PF}_{p}(\$ / \mathrm{GJ})$ is the associated fuel price.

$$
\begin{aligned}
\mathrm{PC} & =\sum_{p} \mathrm{NP}_{p}\left(\mathrm{CCP}_{p}+\mathrm{OMP}_{p}\right) \mathrm{PVF}_{p} \\
& +\sum_{p} \sum_{e \in E_{p}} \mathrm{EP}_{p e}\left(\mathrm{CCP}_{p}+\mathrm{OMP}_{p}\right) \mathrm{EPVF}_{p e}+\mathrm{FP}_{p} \mathrm{PF}_{p} t \mathrm{PVF}_{p}
\end{aligned}
$$

\subsubsection{Hydrogen cost}

The cost of hydrogen production (HC, \$) can be determined as defined in Eq. (34). $\mathrm{NH}_{h}$ and $\mathrm{EH}_{h e}$ are integer and binary variables that indicate the number of new hydrogen plants to be installed and existing plants operating in the investigated year, respectively. The capital cost hydrogen plants is represented by the parameter $\mathrm{CCH}_{h}$ (\$/year) and the operating and maintenance cost by $\mathrm{OMH}_{h}$ (\$/year). Fuel consumption by each hydrogen production technology is presented by the variable $\mathrm{FH}_{h}(\mathrm{GJ} / \mathrm{h})$ and the associated fuel cost is accounted for by the parameter $\mathrm{PF}_{h}(\$ / G \mathrm{~J})$.

$$
\begin{aligned}
\mathrm{HC}= & \sum_{h} \mathrm{NH}_{h}\left(\mathrm{CCH}_{h}+\mathrm{OMH}_{h}\right) \mathrm{PVF}_{h}+\sum_{h} \sum_{e \in E_{h}} \mathrm{EH}_{h e}\left(\mathrm{CCH}_{h}\right. \\
& \left.+\mathrm{OMH}_{h}\right) \mathrm{EPVF}_{h e}+\mathrm{FH}_{h} \mathrm{PF}_{h} t \mathrm{PVF}_{h}+\mathrm{NHE}(\mathrm{CCHE} \\
& +\mathrm{OMHE}) \mathrm{PVF}_{\text {elec }}+\sum_{e \in E_{\text {elec }}} \mathrm{EHE}_{e}(\mathrm{CCHE}+\mathrm{OMHE}) \mathrm{EPVF}_{\text {elec }}
\end{aligned}
$$

\subsubsection{Steam and hot water cost}

The cost of producing SAGD and process steam is calculated as illustrated in Eq. (35). $\mathrm{NB}_{b}$ is the integer variable representing the number of boiler of type $b$ (i.e., natural gas or biomass fueled) producing SAGD extraction and process steam. $\mathrm{ENB}_{b e}$ is the binary variable representing the operation of an existing boiler during an investigated year. $\mathrm{CCB}_{b}$ and $\mathrm{OMB}_{b}$ are the associated capital and operating cost factors for each type of boiler. $\mathrm{XSB}_{b}$ is the amount of fuel consumed by newly installed and existing boilers, and $\mathrm{PFB}_{b}$ is the associated fuel price.

$$
\begin{aligned}
\mathrm{SC}= & \sum_{b} \mathrm{NB}_{b}\left(\mathrm{CCB}_{b}+\mathrm{OMB}_{b}\right) \mathrm{PVF}_{b}+\sum_{b} \sum_{e \in E_{b}} \mathrm{ENB}_{b e}\left(\mathrm{CCB}_{b}\right. \\
& \left.+\mathrm{OMB}_{b}\right) \mathrm{EPVF}_{b e}+\mathrm{XSB}_{b} \mathrm{PFB}_{b} t \mathrm{PVF}_{b}
\end{aligned}
$$

Process hot water is also produced using geothermal heating. The cost of production associated with this technology is estimated as illustrated in Eq. (36), where the capital (CCGEO) and operating (OMGEO) cost factors account for the cost of drilling, sustaining the flow rate of water for a period of 10 years, and providing water at $60^{\circ} \mathrm{C}$ and a flow rate of $50 \mathrm{~L} / \mathrm{s}$ (Pathak et al., 2013).

$$
\begin{aligned}
\mathrm{HWGC}= & \text { NGEO }(\text { CCGEO }+ \text { OMGEO }) \mathrm{PVF}_{g} \\
& +\sum_{e \in E_{G E O}} \mathrm{EGEO}_{e}\left(\mathrm{CCGEO}+{\mathrm{OMGEO}) \mathrm{EPVF}_{g e}}\right.
\end{aligned}
$$

\subsubsection{Extraction fuel (natural gas and diesel) cost}

Diesel and natural gas are consumed in bitumen extraction operations. Diesel is consumed by the trucking and shoveling fleet used in oil sands mining operations and its total cost is calculated by multiplying the total diesel requirements $\operatorname{MEDD}(\mathrm{L} / \mathrm{h})$ by the price of diesel (PD, \$/L). Natural gas is consumed in hydrocracking and thermocracking upgrading operations for SCO production. Total natural gas requirement for integrated SAGD/upgrading and mining/upgrading operations is expressed by the variable UFD (GJ/h), respectively. PNG is the price of natural gas $(\$ / G J)$.

$\mathrm{EFC}=[\mathrm{MEDD} \mathrm{PD}+\mathrm{UFD} \mathrm{PNG}] t \mathrm{PVF}_{f}$ 


\subsubsection{Carbon transportation and sequestration cost}

The transportation and sequestration cost of captured $\mathrm{CO}_{2}$ from power and hydrogen plants is calculated as illustrated in Eq. (37). TC $(\$ /$ ton $/ \mathrm{km})$ and SC (\$/ton) are the unit transportation and sequestration costs of $\mathrm{CO}_{2}$, respectively. $\mathrm{CSCP}_{p}$ and $\mathrm{CSCH}_{h}$ are the amounts of $\mathrm{CO}_{2}$ captured by power and hydrogen plants (ton/h), respectively.

$\mathrm{CCSC}=(\mathrm{TCL}+\mathrm{SC})\left(\sum_{p} \mathrm{CSCP}_{p}+\sum_{h} \mathrm{CSCH}_{h}\right) \mathrm{PVF}_{\mathrm{cCS}}$

The formulated optimization model is directed toward the minimization of the total cost of energy production. It incorporates the individual costs of producing each energy commodity (i.e., power, hydrogen, SAGD steam, process steam, hot water, and fuel). The objective function also incorporates the carbon capture and sequestration costs. The optimization model searches for the set of energy commodity producers, as well as bitumen and SCO producers that minimize the total cost of oil sands operations while being subject to $\mathrm{CO}_{2}$ emission constraints.

Minimize NPV $=\mathrm{PC}+\mathrm{HC}+\mathrm{SC}+\mathrm{HWGC}+\mathrm{EFC}+\mathrm{CCSC}$

\subsection{Energy supply}

The total energy commodity requirements for oil sands extraction and upgrading operations must be satisfied by the supply from the energy producers. The supply constraints defined in Eqs. (40)-(44) specify that the total amounts energy commodities produced from newly established and existing energy producers must be greater than or equal to that required by oil sands operations.

$$
\begin{aligned}
& \sum_{p} \mathrm{PP}_{p}+\sum_{h \in H_{\mathrm{CO}}} \mathrm{PH}_{h} \geq \mathrm{MEPD}+\mathrm{SEPD}+\mathrm{UPD}+\mathrm{SMRPD}+\mathrm{CCPD} \\
& \sum_{h} \mathrm{HH}_{h}+\mathrm{HHE} \geq \mathrm{UHD} \\
& \sum_{b} \mathrm{SS}_{b} \geq \mathrm{SESD} \\
& \sum_{b} \mathrm{PS}_{b} \geq \mathrm{MEPSD}+\mathrm{UPSD} \\
& \sum_{b} \mathrm{HW}_{b}+\mathrm{GW} \geq \mathrm{MWD}
\end{aligned}
$$

\section{Case study}

The developed renewable energy capacity expansion optimization model for the oil sands industry was applied to consecutive operational periods (i.e., 2010, 2015, 2020 and 2025). The results of one operational period were used as an input for the following periods, for which capacity expansion decisions were optimized. Data for oil sands production levels (i.e., bitumen and SCO), producers' capacities, techno-economic data of energy producers, fuel prices, and environmental regulations for these operational years are readily available in the literature. Different scenarios were considered to illustrate the benefits of incorporating renewable energy technologies and capacity expansion decisions in the oil sands energy optimization model. The sequential approach is applied, in which the results of one operational year are used as an input for the following investigated period, and was investigated with and without the incorporation of renewable energy technologies (Fichter et al., 2014a,b). In the sequential approach the existence of a mix of energy infrastructure influences investment decisions in the following investigated period. The preference of the model to
Table 4

Key techno-economic parameters (Ordorica-Garcia et al., 2007; Ordorica-Garcia et al., 2008; Betancourt-Torcat et al., 2011; Betancourt-Torcat et al., 2012a; Betancourt-Torcat et al., 2013).

\begin{tabular}{ll}
\hline Parameter & Value \\
\hline Boiler feed water cost $\left(\$\right.$ ton $\left.^{-1}\right)$ & 1.5 \\
Coal cost $\left(\$ \mathrm{GJ}^{-1}\right)$ & 3.0 \\
Diesel cost $\left(\$ \mathrm{~L}^{-1}\right)$ & 1.5 \\
Natural gas cost $\left(\$ \mathrm{GJ}^{-1}\right)$ & $7.3-9.6$ \\
$\mathrm{CO}_{2}$ transport cost $\left(\$ 100 \mathrm{~km} \mathrm{ton}^{-1}\right)$ & 1.4 \\
$\mathrm{CO}_{2}$ injection cost $\left(\$\right.$ ton $\left.^{-1}\right)$ & 8.0 \\
$\mathrm{Natural}^{-1}$ gas heating value $\left(\mathrm{MJ} \mathrm{Nm} \mathrm{Nm}^{-3}\right)$ & 38.05 \\
Coal heating value $\left.(\mathrm{MJ} \mathrm{kg})^{-1}\right)$ & 24.05 \\
Biomass heating value $\left(\mathrm{MJ} \mathrm{kg}^{-1}\right)$ & 20.5 \\
Biomass availability $\left(\right.$ ton $\left.\mathrm{h}^{-1}\right)$ & 740 \\
Annual operating hours $\left(\mathrm{h} \mathrm{year}^{-1}\right)$ & 8,760 \\
Boiler's capacity for process steam $(\%)$ & 0.82 \\
$\mathrm{CO}_{2}$ emission base case $\left(\right.$ ton $\left.^{-1}\right)$ & 9195
\end{tabular}

incorporate new technologies (e.g., renewable energy) in the new energy mix is dependent on the technologies in the existing infrastructure. The production capacity of oil producers is also affected by the energy production technologies included. An increment of five years is considered between the investigated operational years, which is used by decision makers to review investment decision in the oil sands industry (Anon, 2006).

Table 2lists the oil and energy producers incorporated in the model. The oil producers included in the investigated case study depend on the oil sands extraction method and upgrading route. The two considered extraction methods are oil sands mining and in-situ SAGD. Each extraction method can be possibly integrated with any of the three considered upgrading routes. The upgrading routes can be based on hydrocracking, thermocracking, or a combination of both. The technology considered for the hydrocracking only route is high conversion LC-fining. Delayed coking was the technology considered for the thermocracking upgrading route. Low-conversion LCF plus fluid coking was considered for the combined hydrocracking and thermocracking. Hydrotreatment is a required stage in all upgrading routes. The energy producers incorporated include technologies for the production of SAGD steam, process steam, hot water, hydrogen, and power.

The individual cost parameters, fuel rates and emission factors for each energy commodity producer are summarized in Table 3, and other key economic parameter required for the model are summarized in Table 4.

The input data dependent on the specific operation period investigated include total bitumen and synthetic crude oil production levels, fuel prices, and emission targets. The values for these inputs for the operational periods investigated are summarized in Table 5.

\section{Results and discussion}

A stepwise capacity expansion optimization for the Alberta oil sands energy infrastructure has been conducted for a time frame of ten years (i.e., 2015-2025). For the planning steps 2015, 2020 and 2025, the capacity expansion of the energy infrastructure was optimized. Two scenarios were considered for the planning period

\begin{tabular}{|c|c|c|c|c|}
\hline & 2010 & 2015 & 2020 & 2025 \\
\hline SCO production (bbl day ${ }^{-1}$ ) & 570,000 & 943,471 & $1,490,000$ & $1,900,000$ \\
\hline Bitumen production (bbl day ${ }^{-1}$ ) & 400,000 & 566,082 & $1,290,000$ & $1,480,000$ \\
\hline Natural gas price $\left(\$ \mathrm{GJ}^{-1}\right)$ & 7.3 & 8.0 & 9.0 & 9.6 \\
\hline $\mathrm{CO}_{2}$ emission target $(\%)$ & 0 & 15 & 30 & 52 \\
\hline
\end{tabular}
investigated. The first scenario involved the inclusion of renewable

Table 5

Data for the investigated periods (Canadian Association of Petroleum Producers (CAPP), 2014; McColl et al., 2008). 
Table 6

Total production from mining and SAGD oil producers, and their energy requirements for both the renewable and conventional energy scenarios over the planning period (2015-2025).

\begin{tabular}{|c|c|c|c|c|c|c|}
\hline & \multicolumn{3}{|c|}{ Renewable } & \multicolumn{3}{|c|}{ Conventional } \\
\hline & 2015 & 2020 & 2025 & 2015 & 2020 & $2025^{a}$ \\
\hline Total mined SCO $\left(\mathrm{TB} \mathrm{day}^{-1}\right)$ & 500 & 691 & 910 & 500 & 794 & 965 \\
\hline Total SAGD SCO $\left(\right.$ TB day $\left.^{-1}\right)$ & 443 & 799 & 990 & 443 & 696 & 935 \\
\hline Total SCO $\left(\right.$ TB day $\left.^{-1}\right)$ & 943 & 1490 & 1900 & 943 & 1490 & 1900 \\
\hline Total bitumen ( $\mathrm{TB} \mathrm{day}^{-1}$ ) & 567 & 1290 & 1480 & 567 & 1290 & 1480 \\
\hline \multicolumn{7}{|l|}{ Energy demand } \\
\hline Power (MWh) & 817 & 1215 & 1450 & 817 & 1323 & 1687 \\
\hline SAGD steam $\left(\mathrm{kt} \mathrm{h}^{-1}\right)$ & 16 & 36 & 38.9 & 16 & 33 & 37.7 \\
\hline Water $\left(\mathrm{kt} \mathrm{h}^{-1}\right)$ & 24 & 29 & 42 & 24 & 31 & 44 \\
\hline Process steam $\left(\mathrm{kt} \mathrm{h}^{-1}\right)$ & 3.8 & 5.3 & 7.4 & 3.8 & 5.6 & 7.9 \\
\hline Diesel $\left(\mathrm{kLh}^{-1}\right)$ & 37 & 42 & 66.8 & 37 & 48 & 67.9 \\
\hline Hydrogen $\left(\mathrm{th}^{-1}\right)$ & 149 & 253 & 305 & 149 & 235 & 323 \\
\hline Natural gas $\left(\mathrm{Mm}^{3} \mathrm{~h}^{-1}\right)$ & 1.1 & 2.3 & 3.1 & 1.5 & 2.5 & 2.9 \\
\hline Coal $\left(\mathrm{kt} \mathrm{h}^{-1}\right)$ & 1.3 & 2.4 & 2.0 & 1.3 & 2.2 & 2.8 \\
\hline Biomass $\left(\mathrm{kt} \mathrm{h}^{-1}\right)$ & 0.74 & 1.5 & 2.2 & NA & & \\
\hline
\end{tabular}

a The results shown for this scenario are those obtained for the maximum emission reduction target (37\%) achieved by the conventional energy mix. This value is lower than the emission reduction target required for the year 2025 (52\%).

technologies in the energy infrastructure, while the second only incorporated conventional fossil fuel based technologies. The input data to the optimization model include the total production rates of bitumen and synthetic crude oil, techno-economic data of existing and new energy production technologies, $\mathrm{CO}_{2}$ emission constraints, and fuel prices (i.e., natural gas, coal and diesel). The results for the year 2010 were used as the initial energy infrastructure and used as an input for the following year. This was assumed to be the existing energy production capacity. The model simultaneously selects the optimal set of SCO and bitumen producers, quantifies their energy requirements, and selects a set of energy commodity producers that will meet the energy demands at minimum costs while complying with the imposed $\mathrm{CO}_{2}$ emission constraints. In the capacity expansion model the results of one planning step were used as input for the next planning step. This data includes the number of units and techno-economic data of energy production plants installed (i.e., existing technologies). It also includes the production capacities of oil producers, which is used as a lower bound for the production capacities of producers in the following period.

Table 6 shows a summary of the total production volumes of mined and SAGD produced synthetic crude oil and the total energy requirements over the planning period (2015-2025) for both the renewable and conventional energy scenarios. For the renewable energy scenario the total integrated SAGD upgrading capacity is higher for the entire planning period in comparison to the scenario in which only fossil fuel-based technologies are considered. On the other hand, integrated mining upgrading capacity constitutes a higher share of total synthetic crude oil production in the conventional energy scenario. The total production of commercial bitumen is achieved through only SAGD extraction as its production route in both the renewable and conventional energy scenarios. The total requirements for each energy commodity depend on the total production capacities of integrated mining/upgrading, integrated SAGD/upgrading and SAGD extraction for commercial bitumen. For example, the higher production level of integrated SAGD/upgrading for the renewable energy scenario results in a higher amount of SAGD steam requirements over the planning in comparison to the conventional energy scenario. Similarly the requirement of hot water, process steam and diesel, which are extensively used in mining extraction, is higher for the conventional energy scenario due to the higher production capacity of integrated mining/upgrading.

The requirements for each energy commodity also depend on the type of upgrading route integrated with the extraction method. For integrated mining/upgrading four production routes have been considered, which include a combination of thermal and hydrogen cracking (MP1), a combination of thermal and hydrocracking and an additional conditioning stage for extraction (MP2), thermal cracking (MP3), and hydrocracking (MP4). For integrated SAGD/upgrading three upgrading routes were also considered, which include a combination of thermal and hydrogen cracking (SP1), thermal cracking (SP2), and hydrogen cracking (SP3). Fig. 4 shows the distribution of synthetic crude oil production among the considered production routes over the planning period. The upgrading routes that contribute the highest share (up to $75 \%$ ) of synthetic crude oil production are based on hydrocracking (MP2, MP4 and SP3). MP4 and SP3 were selected among the most suitable integrated mining/upgrading and SAGD/upgrading SCO producers, because they are based on the highest conversion hydrocracking production routes, which yield higher SCO conversion compared to thermocracking processes and other hydrocracking routes. The hydrocracking production routes are characterized by having higher conversion of bitumen to synthetic crude oil compared to thermocracking-based bitumen upgrading routes. Hydrocracking is a process that involves the utilization of hydrogen to breakdown large molecules in the heavy oil feedstock to smaller molecules, whereas thermocracking relies on the utilization of heat for the cracking process, which is mostly produced from burning natural gas (i.e., process fuel).

Hydrogen can be inexpensively produced through coal gasification plants. Coal is an economical fuel and is considerably lower in cost compared to natural gas (Table 4). However, burning coal results in significantly higher $\mathrm{CO}_{2}$ emissions compared to natural gas due to its higher carbon content. This tradeoff affects the selection of oil producers over the planning period, in which the emission reduction target becomes more stringent over the years, which in return requires cleaner methods of energy production. This can be a contributing factor to the reduction in the percentage share of some of the hydrocracking-based oil producers (i.e., MP4) over the planning period as shown in Fig. 4. Even though the share of some hydrocracking upgrading routes in the total production of synthetic crude oil is decreasing, their total share in production is considerably high. The integrated mining/upgrading routes MP1 and MP2 both have the same upgrading processes; however, MP1 incorporates an additional bitumen treatment stage during the extraction process, which is bitumen conditioning. This step requires the utilization of additional process steam and hot water. The additional requirements of energy commodities by this bitumen processing route reduce the likelihood of its selection by the optimization model.

Fig. 5 shows the distribution of the percentage share of synthetic crude oil production among the oil producers for the conventional energy scenario. It can be observed that the distribution among the synthetic crude oil producers is similar to that obtained for the renewable energy scenario. The only difference that can be observed is in the total share of integrated mining/upgrading routes (MP1-MP4) relative to integrated SAGD/upgrading (SP1-SP3). The share of mining producers in the conventional scenario is higher than that in the renewable scenario. Moreover, the percentage increase in mining producers (MP2) is higher compared to that of SAGD producers (SP3). This is due to the significant steam requirements by SAGD producers, which can only be produced by natural gas boilers in the conventional scenario. SAGD producers' consumption of natural gas is highly intensive compared to mining producers, which results in higher cost of energy production and $\mathrm{CO}_{2}$ emissions. The second factor affecting the selection of oil producers is the type of upgrading route, which can be based on hydrocracking and thermocracking processes. Similar to the renewable energy scenario the largest share of synthetic crude oil production is contributed to by hydrocracking-based upgrading 


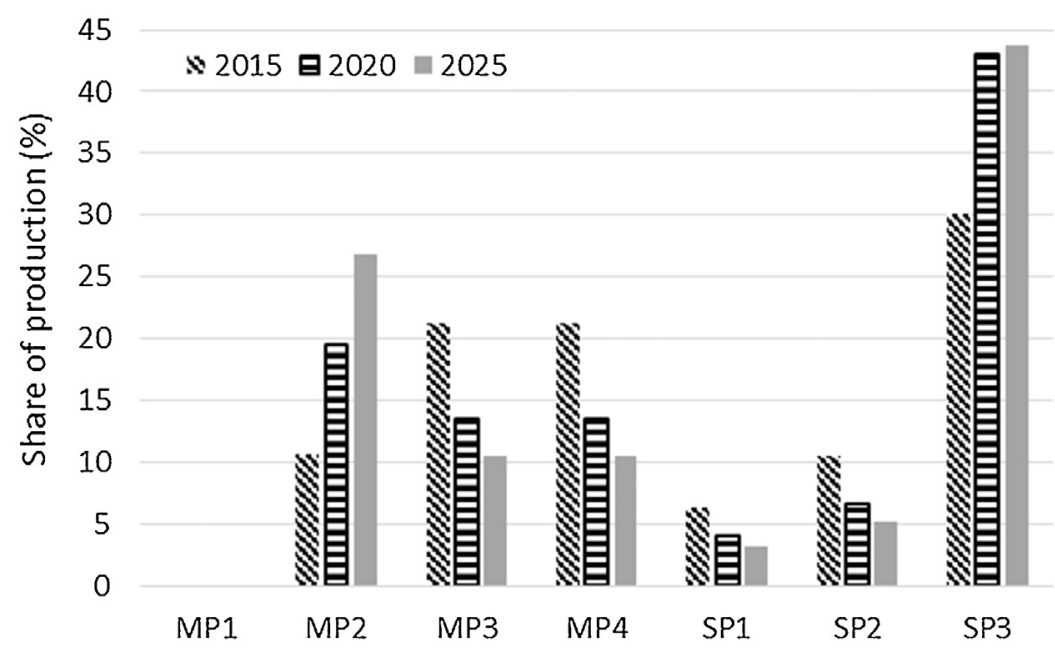

Fig. 4. Distribution of oil proudction among mining and SAGD producers for the renewable scenario over the planning period (2015-2025).

routes (MP2, MP4 and SP3). This is due to the availability of coal gasification in the optimization model, which results in hydrogen production being more economically attractive than utilizing natural gas for heat production in thermocracking upgrading processes.

The highest increase in the share of oil producers in the production capacity is attributed to mining production routes. The production of SCO through integrated mining/upgrading technologies represents a more preferable route compared to SAGD operations. This is due to the significant steam requirements of SAGD operations, which is mostly satisfied through the use of natural gas boilers. Another reason for favoring mining operations is due to the high steam to oil ratio (SOR) that is based on current SAGD operations, which is 2.4 ton steam/ton bitumen. However, with technological advances the SOR for SAGD extraction is expected to considerably decrease in the future. This is also evident in the comparison between renewable and non-renewable energy production scenarios. In the case were natural gas boilers are the only source of SAGD steam, the production from mining operations is preferred due to the lower process fuel requirements. This trend is likely to continue in the short-term future despite the fact that $80 \%$ of bitumen deposits are only recoverable through in-situ methods, which are expected to contribute significantly to oil sands production given the expected technological advancements that will lead them to become the primary extraction processes. Even though SAGD extraction methods are expected to dominate oil sands operations in the future, a significant portion of their production is expected to be marketed as commercial bitumen instead of being upgraded to SCO. This is because crude bitumen produced through mining operations consists of significant amounts of water and suspended solids making its commercialization unfavorable. An increase in the production capacity of mining operations was accompanied by a significant increase in hot water demand, which can be attained through geothermal direct water heating that has a considerably lower carbon foot print compared to natural gas boilers.

It is important to note that the change in the environmental constraint affects the distribution of oil producers. As the environmental constraints become more stringent, the optimization model will require the selection of energy producers that minimize energy production costs for the imposed constraints. This is in agreement with data reported in the literature, which in indicated that in-situ production results in emissions that are on average 2.5 times higher than those associated with mining operations. Therefore, the model is gravitated toward increasing the capacity of integrated mining/upgrading schemes over integrated SAGD/upgrading schemes. This will in return affect the selection of oil producers, as it will increase reliance on mining based operations to reduce the steam requirements. Moreover, since the emissions from natural gas boilers are not controlled, and they are the only producers for steam and hot water for the scenario where no renewable technologies were considered, the emission constraint for the year 2025 was not met, and a lower emission reduction target was achieved compared to the renewable scenario. However, with the incorporation of renewable technologies, particularly biomass boilers for SAGD steam production and geothermal energy for hot water production, significant GHG emission reductions were achieved. The higher production capacities available from geothermal sources increased the reliance on integrated mining/upgrading production operations.

Fig. 6 shows the cost distribution of the net present value for each investigated scenario. The NPV was used in the cost analysis of the renewable capacity expansion optimization model. The existence of certain energy commodity producers in the oil sands energy infrastructure can affect investment decisions in future operational years. The major energy commodities that contribute to the total cost are hydrogen, SAGD steam production, and process steam production. Hydrogen is used extensively for the upgrading of bitumen to SCO in hydrocracking, which can comprise up to approximately $85 \%$ of total SCO production. Hydrogen is also extensively used in hydrotreatment processes for the removal of sulfur and other impurities. Since SAGD extraction is the only production route considered for commercial bitumen, SAGD steam represents the most important energy commodity for its production. SAGD steam is also extensively used in the production of SCO through integrated SAGD/upgrading routes considering the high SOR required for their operations. Moreover, process steam is also extensively utilized in oil sands operations as it is required for mining extraction processes, such as hydrotransport and bitumen recovery, as well as for upgrading stages. The total cost of energy production increases with the increase of the $\mathrm{CO}_{2}$ emissions constraints. This is due to the inclusion of $\mathrm{CO}_{2}$ capture technologies, which require an additional energy supply to compensate for the power consumption for the transportation of $\mathrm{CO}_{2}$ through pipelines to the underground sequestration sites. This imposes the requirement of additional independent power suppliers to satisfy the increased demand.

It can be observed from the results in Fig. 7, which show the total emissions for each operational year for both the renewable and conventional energy scenarios, that the incorporation of renewable technologies in the oil sands energy infrastructure facilitate 


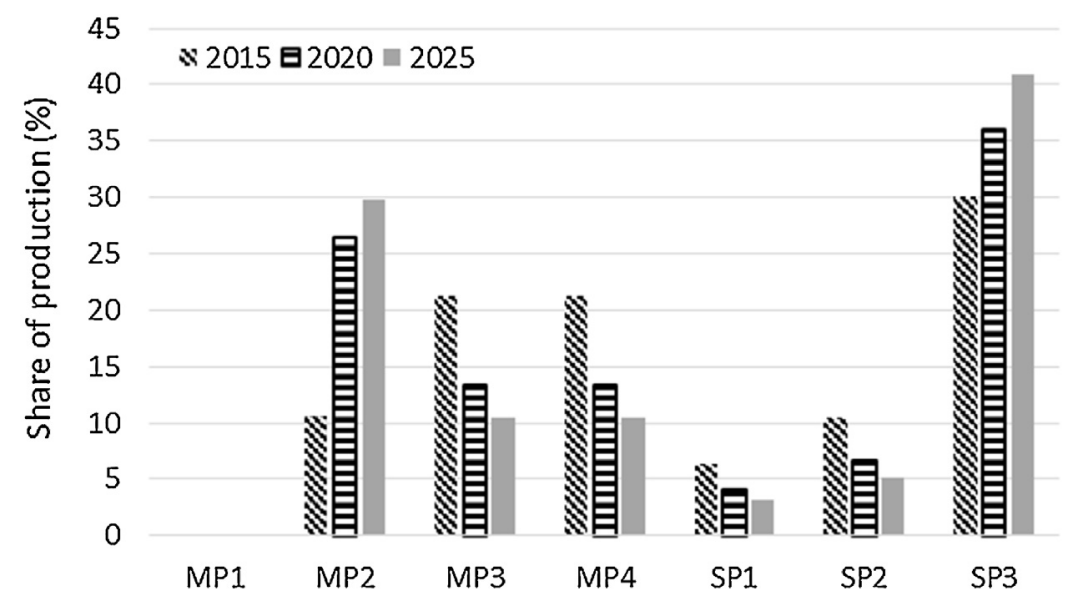

Fig. 5. Distribution of oil proudction among mining and SAGD producers for the conventional scenario over the planning period (2015-2025).

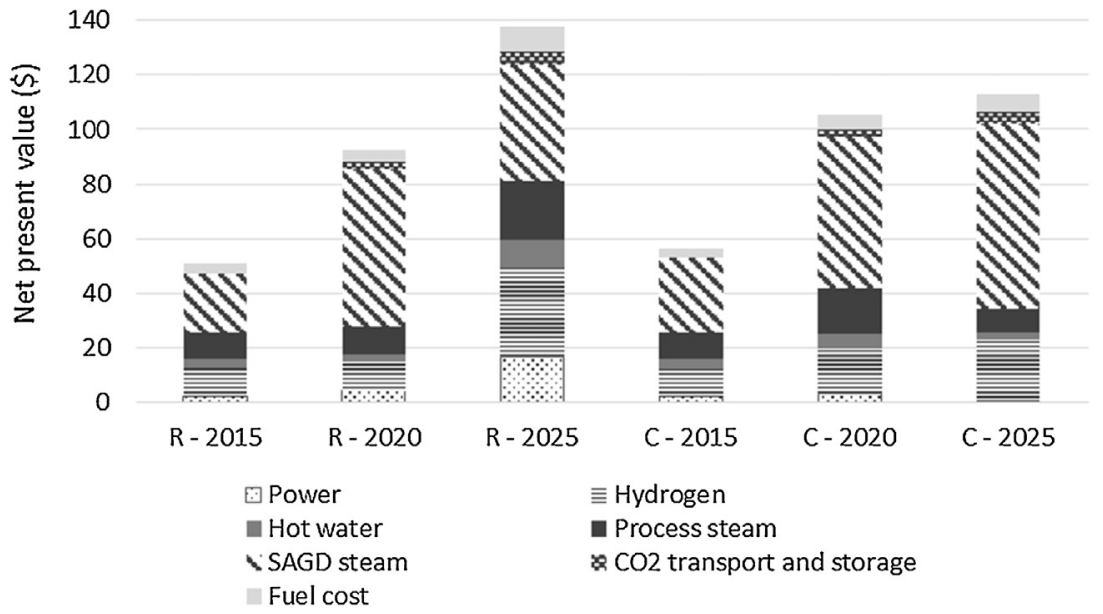

Fig. 6. Cost distribution for the production of energy for both the Renewable (R) and Conventional (C) energy scenarios over the planning periods (2015-2025).

the achievement of higher emission reductions in comparison to conventional energy technologies.

Moreover, the use of renewable energy technologies results in lower total cost of energy production for the same level of emissions reduction. This is particularly evident from the results obtained for the operational year 2020, for which the total cost of energy production was $14 \%$ higher for the conventional energy scenario. For the conventional energy scenario SAGD steam can only be produced through natural gas boilers, while biomass-fired boilers are available for SAGD steam production in the renewable energy scenario. Biomass is considerably lower in cost compared to natural gas (Table 4). In this study the consumption of biomass was assumed to be carbon neutral, from which emissions are considerably lower compared to the consumption of natural gas. Moreover, the availability of geothermal energy for hot water production also significantly contributes to the reduction of natural gas consumption. The unavailability of renewable technologies requires the integration of carbon capture and sequestration into the energy infrastructure in order to be able to comply with the imposed emission constraints. This translates to a substantial increase in the cost of energy production in the conventional energy scenario.

The Alberta government plan to the Kyoto protocol requires the reduction of $\mathrm{CO}_{2}$ emissions from the oil sands industry to a level of at least 50 million tons per year by 2020 , which can be estimated as approximately 6000 tons per $\mathrm{h}$ and will become more stringent in future years. The emission reduction constraint set for the year 2025 (50\%) was not achievable through a fossil-fuel-based energy infrastructure and the optimization model returned an infeasible result. The maximum level of achievable emission reduction for the conventional energy scenario was determined to be $35 \%$, which is equivalent to a total emission level of 5976 ton $\mathrm{CO}_{2} \mathrm{~h}^{-1}$. For the renewable energy scenario an emission reduction level of $52 \%$ was achieved, which corresponds to a total emission level of 4400 ton $\mathrm{CO}_{2} \mathrm{~h}^{-1}$. The higher level of emission reduction achieved in the renewable energy scenario justifies the higher cost required for energy production during the operating year 2025. For the renewable energy scenario the cost of power is relatively high for the year 2025 as the production switches to the lowest emission technology (i.e., NG oxyfuel with CCS) included in the energy infrastructure, from which the majority of power is produced. The increase in the cost of power is driven by a substantial increase in the power demand combined with the higher capital and operating cost of the low-emission technology. The selection of biomass fired boilers for SAGD steam production and geothermal energy for the heat requirements of mining extraction played a significant role in achieving the required emission reduction levels.

Table 7 summarizes the set of energy commodity producers selected by the optimization model and the capacity expansion decisions for both the conventional and renewable energy scenarios over the investigated time period (2015-2025). The majority of hydrogen produced for both the renewable and conventional energy scenarios is achieved through coal gasification plants. Coal is a relatively economical fuel, particularly in comparison with natural gas. Moreover, this type of hydrogen plants can cogen- 


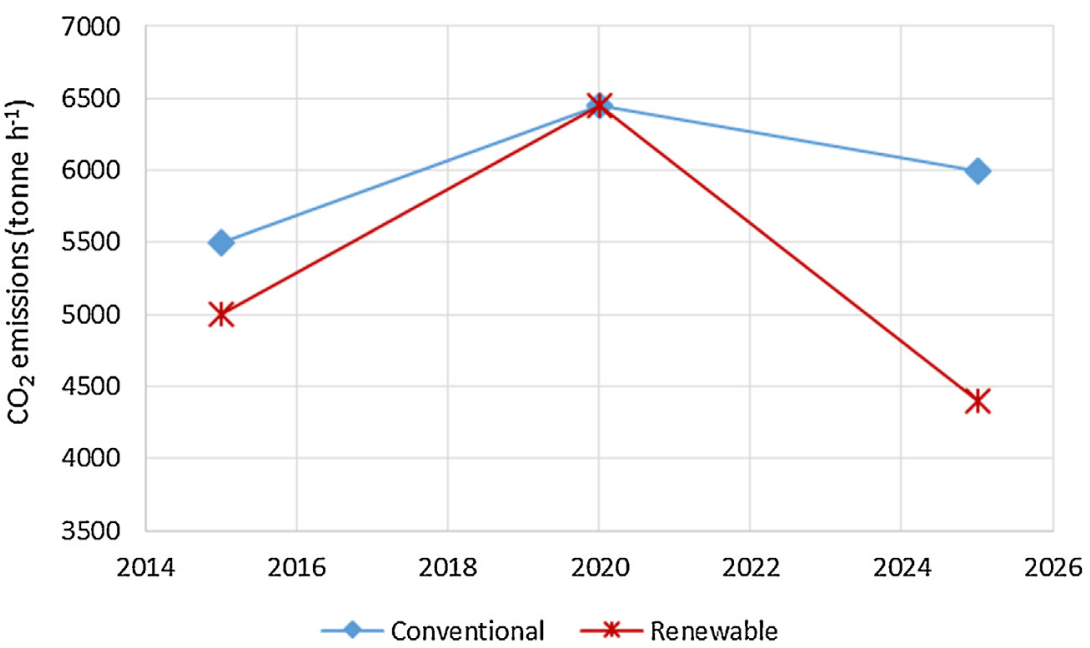

Fig. 7. Carbon dioxide emissions for both the renweable and conventional energy scenarios over the planning periods (2015-2025).

Table 7

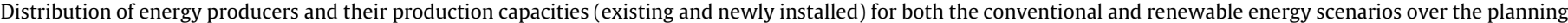
period (2015-2025).

\begin{tabular}{|c|c|c|c|c|c|c|}
\hline \multirow[t]{2}{*}{ Energy producers } & \multicolumn{3}{|c|}{ Renewable } & \multicolumn{3}{|c|}{ Conventional } \\
\hline & 2015 & 2020 & 2025 & 2015 & 2020 & 2025 \\
\hline Hydrogen (ton $\mathrm{h}^{-1}$ ) & 149 & 253 & 331 & 149 & 235 & 301 \\
\hline Existing IGCC & 80 & 80 & 0.0 & 80 & 53 & 0.0 \\
\hline New IGCC & 70 & 0.0 & 0.0 & 70 & 0.0 & 0.0 \\
\hline Existing IGCC wCC & 0.0 & 0.0 & 186 & 0 & 0.0 & 235 \\
\hline New IGCC wCC & 0.0 & 173 & 42 & 0 & 182 & 44 \\
\hline Existing SR wCC & 0.0 & 0.0 & 0.0 & 0.0 & 0.0 & 0.0 \\
\hline New SR wCC & 0.0 & 0.0 & 102.5 & 0.0 & 0.0 & 22.5 \\
\hline Power (MWh) & 817 & 1240 & 2409 & 817 & 1231 & 1449 \\
\hline Existing PC & 0.0 & 0.0 & 0.0 & 0.0 & 0.0 & 0.0 \\
\hline New PC & 0.0 & 472 & 0.0 & 0.0 & 472 & 0.0 \\
\hline Existing NGCC & 452 & 363 & 0.0 & 452 & 409 & 0.0 \\
\hline New NGCC & 0.0 & 0.0 & 0.0 & 0.0 & 0.0 & 0.0 \\
\hline New NG Oxyfuel & 0.0 & 0.0 & 2160 & 0.0 & 0.0 & 0.0 \\
\hline IGCC co-gen & 365 & 195 & 0.0 & 365 & 130 & 0.0 \\
\hline IGCC w CC co-gen & 0.0 & 210 & 277 & 0.0 & 220 & 1449 \\
\hline Steam and Hot water (ton $\mathrm{h}^{-1}$ ) & 44,140 & 73,924 & 105,810 & 44,339 & 75,913 & 91,874 \\
\hline Process steam- existing NG boilers & 3063 & 3899 & 5570 & 3063 & 4177 & 5848 \\
\hline Process steam- new NG boilers & 798 & 1451 & 2523 & 998 & 2228 & 3013 \\
\hline Existing NG SAGD boilers & 10,200 & 10,540 & 21,573 & 10,200 & 16,320 & 33,320 \\
\hline New NG SAGD boilers & 321 & 19,720 & 0.0 & 6054 & 15,300 & 4919 \\
\hline Existing biomass SAGD boilers & 0.0 & 5733 & 5751 & NA & NA & NA \\
\hline New biomass SAGD boilers & 5733 & 18 & 0.0 & NA & NA & NA \\
\hline Water-existing NG boilers & 18,120 & 23,062 & 14,921 & 18,120 & 24,709 & 34,593 \\
\hline Water-new NG boilers & 4723 & 8581 & 32,946 & 5904 & 13,178 & 17,822 \\
\hline Existing geothermal & 0.0 & 920 & 1841 & NA & NA & NA \\
\hline New geothermal & 1181 & 0.0 & 20,687 & NA & NA & NA \\
\hline
\end{tabular}

erate electricity, which contribute in providing the electricity requirements of oil sands operations. This makes the production of hydrogen through coal gasification more efficient and economically attractive compared to other options considered in the optimization model. Cogeneration is currently incorporated in the oil sands energy infrastructure as an option to increase energy efficiency by using the output of one technology (e.g., hydrogen) to drive turbines for power generation. As the GHG emission constraint becomes more stringent, the hydrogen production fleet switches to IGCC with integrated carbon capture and sequestration technologies. The incorporation of renewable energy technologies facilitates the utilization of existing-fossil fuel based producers without the requirement of emission mitigation options as overall emissions do not exceed the imposed constraint. For example, for the operational year 2020 lower capacities for CCS are required for power and hydrogen production and there is decreased reliance on less $\mathrm{CO}_{2}$
Table 8

Model computational results for all the investigated scenarios.

\begin{tabular}{|c|c|c|c|c|c|c|}
\hline \multirow[t]{2}{*}{ Configuration } & \multicolumn{3}{|c|}{ Renewable } & \multicolumn{3}{|c|}{ Conventional } \\
\hline & 2015 & 2020 & 2025 & 2015 & 2020 & 2025 \\
\hline Optimality gap (\%) & 0 & 0 & 0 & 0 & 0 & 0 \\
\hline CPU time (s) & 280 & 260 & 280 & 290 & 265 & 296 \\
\hline
\end{tabular}

intensive fossil-fuels (i.e., natural gas), which translates to lower production costs of these commodities.

For the operation year 2025 the majority of hydrogen is still produced through coal gasification integrated with carbon capture. However, the stringent emissions constraint for this operational year requires the utilization of a cleaner fuel (i.e., natural gas). In order to comply with the imposed emissions constraints a por- 
tion of hydrogen is produced through steam methane reforming integrated with carbon capture, which is observed for the results obtained for both the renewable and conventional energy scenarios. The utilization of wind power for the production of hydrogen through water electrolysis was not selected by the optimization model. The hydrogen production capacity of the integrated wind power and electrolysis system is relatively low compared to other hydrogen production technologies in the optimization model. Moreover, the unit cost of hydrogen is considerably high due to the transportation costs from the wind-electrolysis facility in southern Alberta to the bitumen upgrading facilities. The low-emission technology does not justify the high unit production and transportation cost of hydrogen.

The power plants selected by the optimization model for the renewable scenario are natural gas gasification combined cycle (NGCC), pulverized coal (PC) and natural gas oxyfuel technologies. The power infrastructure switches from NGCC and PC to natural gas oxyfuel in order to reduce the total $\mathrm{CO}_{2}$ emissions. Natural gas oxyfuel is the lowest emission power production technology in the energy production mix used in the optimization model. Other economical and environmentally friendly options are available for power production, such as biomass gasification. However, the utilization of biomass for power production is limited due to its availability. The biomass feedstock available for energy production for oil the sands operations is used for the production of SAGD steam. For the conventional energy scenario the electricity requirements are mostly satisfied by the power cogenerated from coal gasification plants integrated with carbon capture.

It is evident from the results that the use of renewable energy is important in providing the heat requirements for oil sands operations. A significant portion of SAGD steam is provided by biomass fired boilers and hot water for mining extraction is provided by geothermal energy. These sources of energy were used to replace natural gas boilers in order to achieve the required emission reduction targets. The incorporation of renewable energy technologies plays a vital role in satisfying emission constraints for the year 2025 , and their elimination from the energy infrastructure reduces the maximum achievable emission reduction target. For the conventional energy scenario the maximum reduction of $\mathrm{CO}_{2}$ emissions was determined to be $35 \%$. However, the use of renewable energy facilitates an emission reduction target of $52 \%$.

The developed mathematical models was solved using an Intel Core 2 Duo, $2.33 \mathrm{GHz}$ machine running the DICOPT solver accessed via the general algebraic modeling software (Brooke et al., 1998). The corresponding computational statistics are summarized in Table 8 . The resulting computational times and optimality gaps for the simulation runs are satisfactory.

\section{Conclusions}

An energy optimization model that can be used to determine a well-balanced mix of renewable and conventional energy technologies that can provide the significantly increasing energy demands of Alberta's oil sands industry without increasing reliance on fossil-fuel based and nuclear energy production. The optimization model selects the optimal set of oil sands producers and energy commodity producers that minimizes the total net present value of the oil sands industry. By the large-scale introduction of renewable energy into the oil sands energy infrastructure, considerably higher emissions reductions can be achieved without being offset by the rapidly increasing energy production required to support the developments in the industry.

The model was applied to a case study to illustrate its capability using data for various years of oil sands operations (i.e., 2010, 2015, 2020 and 2025). The results were compared for the sequential (i.e., the results of one year are used as an input for the following) and the non-sequential model approaches. The sequential approach was investigated for both the incorporation and elimination of renewable technologies in the energy infrastructure. The results from the sequential approach indicate that the existing infrastructure has an impact on new investment decisions. Due to the lower cost of existing technologies, the model is more reluctant to switch to cleaner alternatives (i.e., less carbon intensive fuels and renewables). However, the sequential approach provides a more realistic presentation of the oil sands operations.

The results also show that renewable energy technologies have significant potential in reducing emissions from energy production for the oil sands operations. The incorporation of these technologies allowed achieving the same or higher emission reductions at lower total cost of energy production. Moreover, for the year 2025 the emission constraints were considerably high to be achievable using only fossil-fuel based technologies, which resulted in the model becoming infeasible. However, including renewables in the energy mix facilitated the achievement of the required emission reduction levels.

In all the investigated scenarios the model preferred the selection of upgrading routes that are based on hydrocracking processes. This is because hydrogen can be inexpensively produced through coal gasification technologies in addition to coproducing power to be supplied to other oil sands operations. Integrated mining/upgrading production routes were generally favored by the optimization model, which is a trend that is expected to prevail in the short-term future. This is due to the lower steam requirement by these production routes compared to SAGD operations. These production routes require significant amounts of hot water; however, this can be provided by geothermal plants, which are economically attractive and have low carbon emissions associated with them. However, based on oil production forecasts in the literature it is expected that in the long-term future SAGD production routes will be dominant in the production of commercial bitumen and SCO. The provision of steam to support these operations was unfavorable based on the results of the optimization model. Besides the limited resources of steam production from biomass, natural gas boilers were the only other production routes for which carbon mitigation options were not incorporated. This will hinder the achievement of the desirable emission reductions, and therefore, in future work it is important to consider other less carbon intensive alternatives for steam production in the energy infrastructure (e.g., steam production from nuclear energy).

The results obtained indicate that the proposed energy optimization model is a powerful tool that allows the scheduling and planning of future production scenarios of oil sands operations. However, the disadvantage of the proposed model is that it does not involve the optimization of the entire planning time frame at once. The results obtained from optimizing the entire time frame are expected to be different from the sequential approach used in this paper. This can be accounted for by the incorporation of a time index in the energy optimization model, which will be addressed in future work. This will also facilitate the incorporation of time variable parameters, such as oil production levels, fuel prices, government emission regulations, construction lead times, etc. Accordingly, the authors are currently working on the development of a multi-period energy optimization model to represent the operations of the Canadian oil sands industry.

\section{References}

Alberta Electric System Operator (AESO), 2012. Wind Power in Alberta, Available online: http://poweringalberta.com/wp-content/uploads/2015/01/Wind power_in_Alberta_WEB.pdf.

Anon, 2004. Refining Process Handbook. Hydrocarbon Processing Magazine, Gulf Publishing Company, Houston, TX. 
Anon, 2006. Investing in our Future: Responding to the Rapid Growth of Oil Sands Development, Available online:

http://www.energy.alberta.ca/pdf/OSSRadkeReportInvesting2006.pdf (accessed December 2014).

Anon, 2014. Implications of a 2, Available online: http://awsassets.wwf.ca/ downloads/wwf_globalwarming

implicationsof2degressoncanadawaterresources.pdf (accessed November 2014).

Bartholomy, O., 2005. Renewable hydrogen from wind in California. In: Proceedings, National Hydrogen Association Annual Conference, March 29-April 1, 2005, Washington, D.C.

Betancourt-Torcat, A., Guiterrez, G., Elkamel, A., Ricardez-Sandoval, L., 2011. Integrated energy optimization model for oil sands operations. Ind. Eng. Chem. Res. 50, 12641-12663.

Betancourt-Torcat, A., Elkamel, A., Ricardez-Sandoval, L., 2012a. Optimal integration of nuclear energy and water management into the oil sands operations. AIChE J. 58 (11), 3433-3453.

Betancourt-Torcat, A., Elkamel, A., Ricardez-Sandoval, L., 2012b. A modeling study of the effect of carbon dioxide mitigation strategies natural gas prices and steam consumption on the Canadian Oil Sands operations. Energy 45, 1018-1033.

Betancourt-Torcat, A., Almansoori, A., Elkamel, A., Ricardez-Sandoval, L., 2013. Stochastic modeling of the oil sands operations under greenhouse gas emission restrictions and water management. Energy Fuels 27, 5559-5578.

Black and Veatch, 2012. Cost Report-Cost and Performance Data for Power Generation Technologies Prepared for the National Renewable Energy Laboratory, Available online: bv.com/docs/reports-studies/nrel-cost-report.pdf.

Bradley, D., 2010. Canada Report on Bioenergy 2010, Available online: http://www. canbio.ca/upload/documents/canada-report-on-bioenergy-2010-sept-152010.pdf (accessed November 2014).

Brooke, A., Kendrick, D., Meeraus, A., Raman, R., 1998. GAMS: A User's Guide, Available online: http://www2.imm.dtu.dk/courses/02724/general_ information/GAMS_userguide/GAMSUsersGuide.pdf.

Canada's Rivers at Risk, 2012. Environmental Flows and Canada's Freshwater Future, Available online: http://assets.wwf.ca/downloads/canadas_rivers_at risk.pdf (accessed November 2014).

Canadian Association of Petroleum Producers (CAPP), 2014. Crude Oil Forecast, Markets \& Transportaion, Available online www.capp.ca/getdoc.aspx? Docld=247759\&DT=NTV

Chiesa, P., Consonni, S., Kreutz, T., Williams, R., 2005. Co-production of hydrogen, electricity, and $\mathrm{CO}_{2}$ from coal with commercially ready technology. Part A: performance and emissions. Int. J. Hydrogen Energy 30, 747

Clarke, T., 2010. Tar Sands Watch: Tar Sands Showdown-Energy Security, Available online: http://www.tarsandswatch.org/files/Energy\%20Security.pdf.

Common Boiler Formulas, 2006. Common Boiler Formulas, Available online: http://steamcombustion.com/files/JBC_Common_Boiler_Formulas.pdf (accessed September 2014).

Demirel, Y., 2012. Energy, Green Energy and Technology. Springer-Verlag London Limited, Available online: http://www.springer.com/cda/content/document/ cda_downloaddocument/9781447123712-c2.pdf?SGWID=0-0-45-1293540p174262962.

Doritsch, D., Huot, M., Partington, P.J., 2010. Canadian Oil Sands and Greenhouse Gas Emissions, Available online: https://www.pembina.org/reports/ briefingnoteosghg.pdf (accessed October 2014).

Doucet, J., 2007. Is Nuclear Technology an Appropriate Alternative to Natural Gas for Alberta's Oilsands?, Available online https://business.ualberta.ca/-/media/ business/centres/cabree/documents/energy/renewables/wooley.pdf.

EPA, 2010. Biomass CHP Catalog-Biomass Conversion Technologies EPA Combined Heat and Power Partnership, Available online: www.epa.gov/chp/documents/biomass_chp_catalog_part5.pdf.

Ferley, P., Hogue, R., Janzen, N., 2014. Impact of Lower Oil Prices on the Canadian Economic Outlook: An Update, Available online: http://www.rbc.com/ economics/economic-reports/pdf/other-reports/opi2.pdf (accessed January 2015).

Fichter, T., Trieb, F., Moser, M., 2014a. Optimized integration of renewable energy technologies into Jordan's power plant portfolio. Heat Transf. Eng. 35 (3), 281-301.

Fichter, T., Trieb, F., Moser, M., Kern, J., 2014b. Optimized integration of renewable energies into existing power plant portfolios. Energy Proc. 49, 1858-1868.

Garcia-Cortes, C., Tzimas, E., Peteves, S.D., 2009. Technologies for coal based hydrogen and electricity co-production power plants with $\mathrm{CO}_{2}$ capture. European Commission Joint Research Centre Institute for Energy, Calgary, Canada (March 2008).

Government of Canada, 2014. Climate: Hourly Wind Speed, Available online: http://climate.weather.gc.ca/climateData/generate_chart_e. html? timeframe=1\&Prov=\&StationID=8791\&MeasTypeID=windspd\&cmdB1= Go\&Year=2001\&Month=3\&Day=18\&cmdB1=Go\# (accessed October 2014).

Gray, D., Majorowicz, J., Unsworth, M., 2012. Investigation of the geothermal state of sedimentary basins using oil industry thermal data: case study from Northern Alberta exhibiting the need to systematically remove biased data. J. Geophys. Eng. 9 (1), 534-548

HATCH, 2010. Final Report for Alberta Utilities Commission: Update on Alberta's Hydroelectric Energy Resources, Available online: http://www.energy.alberta. ca/electricity/pdfs/auchydroelectricstudy.pdf (accessed November 2014).
Harrel, G., 2002. Steam System Survey Guide. Report ORNL/TM-2001/263. Oak Ridge National Laboratory, Tennessee, United Sates.

Holm, A., Jennejohn, D., Blodgett, L., 2012. Geothermal Energy Association-Geothermal Energy and Greenhouse Gas Emissions, Available online: http://geo-energy.org/reports/ GeothermalGreenhouseEmissionsNov2012GEA_web.pdf.

Huot, M., Grant, J., 2012. Clearing the Air on Oil Sands Emissions-The Facts about Greenhouse Gas Pollution from Oil Sands Development, Available online: http://www.pembina.org/reports/clearing-the-air-climate-oilsands.pdf (accessed November 2014).

International Energy Agency, 2010. Power Generation from Coal-Measuring and Reporting Efficiency Performance and CO, Available online: https://www.iea. org/ciab/papers/power_generation_from_coal.pdf.

Isfeld, G., 2015. Low Oil to Have Both Positive and Negative Effects on Canadian Economy Ottawa Told, Available online: http://business.financialpost.com news/economy/low-oil-to-have-both-positive-and-negative-effects-oncanadian-economy-ottawa-told (accessed April 2015).

Jechura, J., 2015. Hydrogen from Natural Gas via Steam Methane Reforming (SMR), Available online: http://inside.mines.edu/ jjechura/EnergyTech/07_Hydrogen_ from_SMR.pdf.

Kubik, R., 2013. Canadian Oil Sands-2013 Annual Report, Available online: http:// www.cdnoilsands.com/files/FinancialReports/AnnualReport2013/ 2013\%20Annual\%20Report_Final_english_v001_r6d515.pdf (accessed October 2014).

Kumarappan, S., Joshi, S., MacLean, H.L., 2009. Biomass supply for biofuel production: estimates for the United States and Canada. BioResources 4 (3), 1070-1087

Majorowicz, J., Unsworth, M., Chacko, T., Gray, A., Heaman, L., Potter, D., Schmitt, D., Babadagli, T., 2012. Geothermal energy as a source of heat for oil sands processing in Northern Alberta, Canada. In: Hein, F.J., Leckie, D., Larter, S., Suter, J. (Eds.), Heavy Oil and Oil Sand Petroleum Systems in Alberta and Beyond, vol. 64(1. AAPG Studies in Geology, pp. 1-22.

Maxwell, G., 2004. Synthetic Nitrogen Products-A Practical Guide to the Products and Processes. Kluwer Academic Publishers, New York, New York, USA.

McColl, D., Mei, M., Millington, D., Kumar, C., 2008. Canadian Energy Research Institute-Green Bitumen: The Role of Nuclear, Gasification and CCS in Alberta's Oil Sands, Available online: www.ceri.ca/docs/CERIOilSandsGHG-PartII.pdf.

Mckenna, B., 2015. Oil Prices Could go Lower Bank of Canada, Available online: http://www.theglobeandmail.com/report-on-business/industry-news/energyand-resources/oil-prices-could-go-lower-still-boc-says/article22427436/ (accessed February 2015).

Meyers, R.A., 1984. Handbook of Synfuels Technology. McGraw-Hill, New York.

National Energy Board, 2006. National Energy Board-Canada's Oil Sands Opportunities and Challenges to 2015: An Update, Available online: https:// www.neb-one.gc.ca/nrg/sttstc/crdlndptrlmprdct/rprt/archive/ pprtntsndchllngs20152006/pprtntsndchllngs20152006-eng.pdf (accessed November 2014).

National Energy Strategy, 1992. Chapter 4-Efficiency of Energy Conversion (Chapter 4). Available online: http://www.ems.psu.edu/ radovic/Chapter4 pdf.

Noronha, C., 2015. Canadian Think-Tank: Low Oil Prices may lead Alberta's Oil-heavy Economy to Dip into Recession-The Province, Available online: http://www.theprovince.com/business/ Canadian+thinktank+prices+lead+Albertas+oilheavy+economy+into/ 10726034/story.html (accessed February 2015).

OTPI Canada, 2002. OPTI Canada Long Lake Project Application for Commercial Approval, vol. 1. OPTI Canada, Calgary, Alberta, Canada (Sections A-C).

Oil Sands Discovery Centre, 2014. Facts about Alberta's Oil Sands and its Industry, Available online: http://history.alberta.ca/oilsands/resources/docs/facts sheets09.pdf (accessed October 2014).

Olateji, B., Monds, J., Kumar, A., 2014. Large scale hydrogen production from wind energy for the upgrading of bitumen from oil sands. Appl. Energy 118, 48-56.

Olateju, B., Kumar, A., 2011. Hydrogen production from wind energy in Western Canada for upgrading bitumen from oil sands. Energy 36, 6326-6339.

Ordorica-Garcia, G., Croiset, E., Douglas, P., Elkamel, A., Gupta, M., 2007. Modeling the energy demands and greenhouse gas emissions of the Canadian Oil Sands industry. Energy Fuels 21, 2098-2111.

Ordorica-Garcia, G., Elkamel, A., Douglas, P.L., Croiset, E., Gupta, M., 2008. Energy optimization model with $\mathrm{CO}_{2}$-emission constraints for the Canadian Oil Sands Industry. Energy Fuels 22, 2660-2670.

Pathak, V., Babadagli, T., Majorowicz, A., Unsworth, M., 2013. Evaluation of engineered geothermal systems as a heat source for oil sands production in Northern Alberta. Nat. Resour. Res. 23 (2), 247-265.

Price Water House Coopers, 2009. Alberta Environment-Assessment of Selected Renewable Energy Technology and Potential in Alberta, Available online: eipa. alberta.ca/media/42554/ assessment\%20of\%20selected\%20renewable\%20energy\%20technology\%20and \%20potential\%20in\%20alberta.pdf (accessed September 2014).

Rubin, E.S., Rao, A.B., Chen, C., 2004. Comparative assessments of fossil fuel power plants with $\mathrm{CO}_{2}$ capture and storage. In: Proceedings of the GHGT-7 Conference, September 2004, Vancouver, Canada.

Sarkar, S., Kumar, A., 2010. Biohydrogen production from forest and agricultural residues for upgrading of bitumen for oil sands. Energy 35, 582-591.

Schumacher, M., 1982. Heavy Oil and Tar Sands Recovery and Upgrading International Technology. Noyes Data Corporation, Park Ridge, NJ. 
Simbeck, D., Chang, E., 2002. Hydrogen Supply: Cost estimate for Hydrogen Pathways-Scoping Analysis Report NREL/SR-540-32525. National Renewable Energy Laboratory, Colorado, United States.

Simbeck, D.R., 2004. Hydrogen costs with $\mathrm{CO}_{2}$ capture. In: Proceedings of the GHGT-7 Conference, September 2004, Vancouver, Canada.

Sttaffel, I., 2012. Wind Turbine Power Curves, Available online: https://www. academia.edu/1489838/Wind_Turbine_Power_Curves (accessed October 2014).

Sunderland, B., 2001. Hydrogen production, recovery and use at syncrude. In: EFI Conference on Technologies to Enable the Hydrogen Economy, Tucson, AZ.

Van Driesen, R., Caspers, J., Campbell, A.R., Lunin, G., 1979. LC-fining upgrades heavy crudes. Hydrocarbon Process 58 (5).
World Oil Outlook, 2014. Organization of the Petroleum Exporting Countries, Available online: http://www.opec.org/opec_web/static_files_project/media/ downloads/publications/WOO_2014.pdf (accessed January 2015).

Woynillowicz, D., 2005. Oil Sands Fever-The Environmental Implications of Canada's Oil Sands Rush, Available online: https://www.pembina.org/reports/ OilSands72.pdf (accessed December 2014).

Yui, S., Chung, K., 2001. Processing oil sands bitumen is Syncrude's R\&D focus. Oil Gas J. 99 (17), 46-53. 